CAHIERS DE

NARRATOLOGIE

\section{Cahiers de Narratologie}

Analyse et théorie narratives

17 | 2009

Stéréotype et narration littéraire

\title{
Du poncif etc... Le cas des Moralités légendaires de Jules Laforgue
}

\section{Alissa Le Blanc}

\section{(2) OpenEdition}

Journals

Édition électronique

URL : http://journals.openedition.org/narratologie/1167

DOI : 10.4000/narratologie. 1167

ISSN : 1765-307X

Éditeur

LIRCES

\section{Référence électronique}

Alissa Le Blanc, "Du poncif etc... Le cas des Moralités légendaires de Jules Laforgue », Cahiers de Narratologie [En ligne], 17 | 2009, mis en ligne le 22 décembre 2009, consulté le 15 novembre 2019. URL : http://journals.openedition.org/narratologie/1167; DOI : 10.4000/narratologie.1167

Ce document a été généré automatiquement le 15 novembre 2019.

\section{(c) (i) (9)}

Cahiers de Narratologie - Analyse et théorie narratives est mis à disposition selon les termes de la licence Creative Commons Attribution - Pas d'Utilisation Commerciale - Pas de Modification 4.0 International. 


\title{
Du poncif etc... Le cas des Moralités légendaires de Jules Laforgue
}

\author{
Alissa Le Blanc
}

I. Terminologie du « déjà dit » : du stéréotype au poncif

1 Avant d'amorcer cette réflexion sur l'œuvre laforguienne, il nous parait indispensable de préciser ce que nous entendons par le terme de « poncif ». Il s'agira notamment de le situer dans le champ sémantique de la stéréotypie. Commençons par remarquer que les mots « lieu commun », « topos » et « topique » sont issus de la terminologie rhétorique, tandis que d'autres, comme "stéréotype ", "cliché» ou "poncif», ont une origine technique plus tardive : ils désignent tous à l'origine un processus de reproduction, que ce soit dans le domaine des arts ou de l'imprimerie. Dans les deux cas, ces substantifs ont connu une dépréciation progressive, pour en venir à désigner des formes, des contenus ou des représentations banalisées, perçues comme éculées. Cependant, les sciences humaines se sont souvent réapproprié ce vocabulaire en atténuant sa dimension axiologique : en témoigne par exemple le sens précis désormais attribué à « cliché » en stylistique.

2 Assez savant, topos, souvent absent des dictionnaires, est a priori le synonyme exact de « lieu commun ", puisque cette dernière expression, traduction littérale de la locution latine loci communes, se présente elle-même comme un calque du grec koinos topos. Topoï ou lieux communs désignent à l'origine "les sources où un orateur peut puiser des pensées et des preuves sur tous les sujets » (Dictionnaire historique de la langue française Le Robert) ou encore « les types d'arguments communs aux trois genres de rhétorique ${ }^{1}$ ». Ils ressortissent donc, dans la tradition rhétorique aristotélicienne, à l'inventio : un «topique » est synonyme de «lieu commun », tandis que «la topique », qui réfère au célèbre traité d'Aristote, englobe l'ensemble de ces thèmes et arguments "communs ", qui se trouvent à la disposition de l'orateur et à la portée de tous². Comme souvent, la spécialisation sémantique de ces termes a laissé place à un sens élargi ; dans le cas qui nous occupe, ce dernier a évolué vers une acception dévalorisante: on sait qu'après avoir désigné, sans nuance dépréciative, des «traits généraux qui s'appliquent à tout » (Littré), l'expression « lieu commun » en est ainsi venue à recouvrir « ce qui constitue le 
fond rebattu des conversations, des textes et des discours " (Littré). De même, un topos réfère aujourd'hui, au sens courant, à un thème ou à un argument dépourvus de nouveauté, jugés surexploités ${ }^{3}$. Il n'est pas anodin de constater que cette évolution sémantique illustre d'une certaine manière le déclin progressif de la rhétorique classique, et la suspicion croissante en laquelle elle a été tenue.

Les termes de " poncif » et de " cliché » sont de création beaucoup plus récente. Comme le mot «stéréotype », ils proviennent de l'argot typographique et du lexique artistique technique ; comme nous l'avons rappelé, tous trois désignent au départ un procédé de reproduction en série. Bien avant d'acquérir son acception moderne, "stéréotype " s'emploie ainsi en typographie pour nommer un caractère de fonte (fin du dix-huitième siècle). De même, avant de dénoter une expression ou une idée banales, un "cliché " correspond à l'empreinte d'une forme fabriquée «en y coulant un métal fusible permettant d'obtenir une planche solide " (Dictionnaire historique de la langue française Le Robert). Cette plaque métallique en relief permet de "tirer un grand nombre d'exemplaires d'une composition typographique, d'un dessin, d'une gravure sur bois, sans avoir à composer, dessiner ou graver à nouveau " (Trésor de la langue française). Le "stéréotype » devient alors au début du dix-neuvième siècle une forme particulière de cliché en relief. L'emploi figuré de "cliché " comme "phrase ou idée rebattue " (Dictionnaire historique de la langue française Le Robert) ne tarde pas à suivre son utilisation technique dans le domaine de la photographie, que l'on situe aux alentours de 1865. En revanche, le terme générique de "stéréotype " ne connait son acception moderne qu'au vingtième siècle. On peut le définir avec Ruth Amossy comme «un schème collectif figé, un modèle culturel ou une représentation simplifiée propre à un groupe ${ }^{4}$ "; si le mot possède de fortes connotations disciplinaires et renvoie avant tout au champ des sciences sociales, dans le domaine des études littéraires, il peut en fait être considéré comme un hyperonyme subsumant les différentes modalités de schématisation et de figement de la représentation ou de l'expression, quel que soit le médium considéré (mentalités, langue, peinture, cinéma, etc.) En ce sens, clichés, poncifs, lieux communs, topiques et topoï, participent tous de la stéréotypie.

4 Issu de la terminologie des arts décoratifs ${ }^{5}$, le nom " poncif » a été créé dès le seizième siècle; il a suivi une évolution sémantique comparable à celle des termes plus récents de «stéréotype » et de "cliché ». Un poncif désigne toujours aujourd'hui, au sens propre, un « papier ou carton sur lequel un dessin quelconque est découpé ou piqué, de manière à pouvoir le reproduire à l'infini moyennant la poncette contenant de la poudre de charbon de bois » (Littré). Deux glissements sémantiques ont introduit une valeur axiologique figurée dans la définition du terme. Le premier, antérieur à 1830, est encore circonscrit au domaine pictural : le poncif est désormais assimilé à un « dessin fait de routine, selon un type et des procédés conventionnels » (Le Grand Robert de la langue française), à un "dessin dans lequel on remarque un certain style convenu, un calque ou une copie très marquée, une routine dont l'artiste ne sort pas " (Littré) ou encore à un "dessin convenu dans le choix du sujet, la composition, les procédés " (Trésor de la langue française). Baudelaire reprend le terme dans sa critique d'art pour le distinguer du chic: tandis que ce dernier vise un faire machinal, « une mémoire de la main $^{6} »$ dont l'artiste abuse, le poncif est plutôt réservé aux poses conventionnelles ${ }^{7}$. Par analogie, le terme est rapidement étendu, au cours du siècle, à la littérature et, plus largement, au discours. Il est alors appliqué, d'une façon très générale, «à ce qui est banal, à ce qui manque d'originalité " (Dictionnaire historique de la langue française Le Robert). Il n'est pas étonnant que ces deux acceptions péjoratives du mot aient été 
forgées au dix-neuvième siècle, qui érigea l'originalité et la quête de l'« l'inédit type ${ }^{8}$ " en valeurs artistiques suprêmes. Cette condamnation du poncif est officialisée par le Grand dictionnaire universel du XIX ${ }^{e}$ siècle de Pierre Larousse, comme l'illustre cet extrait significatif de l'entrée poncif:

On a donné par extension, en littérature, comme en peinture et en sculpture, le nom de poncif aux compositions qui manquent d'originalité et qui semblent faites sur un patron commun. Le "poncif » a longtemps régné en peinture, sous le nom plus noble de tradition; loin d'être réputé ce qu'il est réellement, une marque d'impuissance, il était regardé comme une preuve de goût, de respect des modèles, de docilité à l'enseignement des maîtres. Faire toujours la même chose, d'après des types convenus, passait pour le comble de l'art [...].

5 Les propos partisans du rédacteur encyclopédique suggèrent que l'avènement de la modernité artistique et littéraire est marqué par la conversion d'une tradition fondée sur le principe de mimésis en une logique créatrice où priment l'individualité, la recherche de l'inédit, de l'unique et du singulier. Cette évolution sémantique correspond bien à un changement majeur des critères d'appréciation esthétique, comme le montre le besoin de créer une série de mots désignant des procédés usés et des formes figées jugées banales. En toute logique, le « poncif » et la plupart des autres termes qui dénotent l'imitation ou la répétition se sont vu progressivement déconsidérer. Si « lieu commun » et topos pâtissent de la déconsidération progressive de la rhétorique, la nuance figurée péjorative qu'acquièrent à l'ère moderne les termes de "poncif», de "cliché" et de "stéréotype », doit certainement au fait que leur référent s'inscrit à l'origine dans une série, marquée par la réitération de l'identique. Reproduction et dévaluation entretiennent en effet des liens symboliques étroits. Ce serait ici le lieu de convoquer les analyses de Walter Benjamin sur le " déclin de l'aura " ("Verfall der Aura») "à l'ère de la reproductibilité technique». Atteinte dans son unicité, l'œuvre reproduite, comme frappée d'une dilution dégradante de son unicité dans le multiple, subit un véritable processus de déperdition ontologique et qualitative. Dans une vision toute platonicienne, ses reproductions ne sont plus que reflets, calques, ombres, "pâles copies", auxquelles manque désormais l'essentiel. En un sens, l'évolution sémantique des termes reflète un changement de paradigme esthétique et sociétal, marqué par une valorisation accrue de l'originalité, du tempérament et de la rupture, au détriment de la tradition et de la convention. Ruth Amossy note à juste titre que "[d]epuis le XIX ${ }^{\mathrm{e}}$ siècle, friand d'originalité et de singularité, tout ce qui se répète et tombe dans le domaine public est ipso facto déprécié 9.» Cette recherche de l'inédit s'accompagne inévitablement d'une condamnation esthétique de la reprise des modèles, au nom d'un rejet de l'imitation, qui a dominé pendant des siècles le champ culturel et artistique. Nous sommes d'ailleurs les héritiers de cette conception de la création, et avons souvent bien du mal à nous défaire de tels postulats, que ce soit dans nos goûts ou nos jugements critiques. Les termes de "stéréotype ", de "cliché", de poncif, de topos, de topique et de lieu commun sont désormais marqués du sceau de la banalité et de l'usure, connotation devenue à la longue dénotation. Or, cette péjoration intrinsèque rend difficile une approche objective des phénomènes de stéréotypie, ce qui explique pourquoi la critique littéraire s'est depuis longtemps réapproprié ce vocabulaire, en réduisant notamment la part subjective attachée aux acceptions communes.

6 À côté du terme générique de stéréotype, ceux de cliché, de poncif, de lieu commun et de topos ont acquis des significations assez fines, dont la critique littéraire a su se saisir 
avec profit. Dans son acception courante la plus vague, cliché est facilement synonyme de stéréotype (au sens le plus social du terme), d'idée reçue ou d'idée toute faite, et possède souvent une connotation de simplification, voire d'inexactitude. Il peut lui aussi référer à des représentations latentes qui relèvent notamment de l'étude des «mentalités ». Cependant, cliché possède aussi une signification stylistique bien précise, qu'exploite par exemple Anne-Marie Perrin Naffakh dans sa thèse consacrée au cliché de style en français moderne ${ }^{10}$. Même employé seul, le mot est souvent réservé aux stéréotypes d'expression, et plus particulièrement aux formules de style figées, proches du trope (telles que sein de neige, teint de lys et de rose, cœur d'airain, cultiver la vertu...) D'une manière générale, la critique littéraire restreint souvent la notion de cliché à des phénomènes de stéréotypie d'expression ponctuels et, pour éviter les confusions, il est sans doute judicieux, lorsque l'on dispose de cette précision de vocabulaire, de s'en tenir à cet usage déjà entériné de "syntagme figé ".

De même, il est difficile d'utiliser le terme de lieu commun sans convoquer son arrièreplan antique : employé dans un discours critique, le terme convoque inévitablement la tradition rhétorique et un classement réfléchi des arguments et des thèmes. Dans ce sens, il n'est plus synonyme de banalité, mais renvoie à une réalité historique, et demeure d'ailleurs un concept opérant dans une approche argumentative ou logique. D'une façon analogue, cliché peut désormais désigner un figement lexical ou syntaxique, sans préjuger de la valeur expressive ni de l'originalité de l'énoncé en question.

Comme cliché et lieu commun, topos possède à la fois un sens courant et une acception critique plus restreinte: dans le premier cas, il connote lui aussi un caractère rebattu, mais, dans l'autre cas, ce terme savant gagne également en neutralité : il désignera un thème littéraire ou une configuration narrative privilégiés et récurrents dans un corpus souvent élargi à un genre ou à une époque. C'est ainsi que Michelle Weil définit pour la Sator ${ }^{11}$ un topos narratif comme une "configuration narrative récurrente d'éléments pertinents, thématiques ou formels ", ou encore comme un "mini-canevas (ou mini-scénario) assez récurrent pour être perçu comme topique ${ }^{12}$ ».

Dans ces nouveaux usages, exempts de péjoration, il faut sans doute voir moins une tentative de réhabiliter le stéréotype, qu'une volonté de se doter d'outils conceptuels pour aborder sans parti pris les phénomènes stéréotypiques. Or, la manipulation des concepts envisagés ne va pas sans poser de délicats problèmes de délimitation et d'identification. Comme le remarque Michael Riffaterre dans un développement consacré au cliché,

le trait le plus frappant, qui sert à l'identifier, est le jugement de valeur auquel il

donne lieu [...]. On considère comme cliché un groupe de mots qui suscitent des jugements comme : déjà vu, banal, rebattu, fausse élégance, fossilisé, etc ${ }^{13}$.

$10 \mathrm{Au}$ fond, il semble impossible d'identifier et de délimiter un topos, un cliché ou un poncif de manière objective, puisque leur perception varie dans le temps et avec les récepteurs. La définition même des termes est conditionnée par une dimension subjective inhérente à de telles notions, qui apparaissent avant tout comme des effets de réception. Il nous paraît difficile d'évacuer totalement cet aspect : si l'on abandonne complètement l'idée de péjoration associée aux termes envisagés, comment distinguer un thème fréquent d'un topique, un syntagme figé d'un cliché, un micro-récit récurrent d'un topos narratif? Quel apport supplémentaire ces termes fournissent-ils à la lecture critique des textes s'ils ne dénotent plus la banalité, ou, pour le dire autrement, s'ils ne 
renvoient plus à l'interprétation partiale d'un récepteur (qu'il s'agisse de l'instance auctoriale ou du lecteur) ? Ruth Amossy et Elisheva Rosen rappellent à juste titre :

une situation de discours socio-historique donnée autorise l'appréhension du cliché comme tel: elle détermine les possibilités mêmes de son existence. [...] La dimension de la réception est donc constitutive dans la mesure où le cliché se présente en dernière instance comme un effet de lecture ${ }^{14}$.

11 La reconnaissance des poncifs reste tributaire des compétences d'un sujet interprétant, de sa sensibilité individuelle, de son imprégnation culturelle, et plus généralement d'un cadre historique donné ${ }^{15}$. Une approche diachronique des phénomènes de stéréotypie paraît donc tout indiquée : il s'agit de définir pour qui, dans quelles conditions et à quel moment telle ou telle configuration devient topique. Henri Quéré insiste sur le fait que la forme ou le contenu stéréotypés sont avant tout le résultat d'un processus historique :

au lieu de penser en termes de figement ou de fixité, ne serait-il pas plus juste de parler de mouvement et de plasticité ? Vu sous ce jour, le cliché apparaît plutôt comme la trace d'un procès en suspens ou en puissance, une sorte de forme arrêtée qui oblige à envisager à la fois son surgissement et son émergence et, à l'autre bout de la chaîne, son éventuel dépérissement ${ }^{16}$.

12 Le stéréotype implique une certaine épaisseur temporelle, demande une durée minimale pour se constituer. Plus globalement, il est indissociable d'un changement de paradigme esthétique: sa perception n'intervient qu'à partir du moment où l'originalité est devenue un objectif artistique ; dans le détail, l'identification de tel ou tel cliché particulier relève d'une lassitude perceptive, de nature à la fois culturelle et individuelle. Les termes de cliché, de topos, de stéréotype ou de poncif conviennent donc parfaitement pour cerner des perceptions subjectives, centrées autour de l'usure des formes et des motifs. Lorsque l'on souhaite simplement étudier des phénomènes de récurrence, indépendamment du jugement de valeur qu'ils peuvent susciter, on gommera la connotation péjorative des termes cités, ou on leur préfèrera des désignations moins équivoques, comme figement, stabilisation, fréquence, répétition, reprise, permanence, persistance, résurgence...

13 Le terme de poncif, rarement utilisé par la critique, a au moins le mérite de ne pas être ambigu sur ce point. En effet, il n'a pas encore acquis de «neutralité » descriptive : en un mot, il ne renvoie jamais au seul figement du contenu ou de l'expression, mais préjuge de ce figement en l'assimilant explicitement à une dévaluation sémantique et esthétique. Par ailleurs, il faut noter que, sans autre précision, le poncif n'a pas de forme préétablie: il peut s'agir aussi bien d'une expression, que d'un thème, d'une image ou même d'une œuvre entière, de faits stylistiques ou syntaxiques, d'expressions figées et de collocations, de récurrences lexicales, mais aussi d'agencements argumentatifs ou narratifs, ou encore de codes génériques, d'idées, de modèles, de représentations non verbales.... Le support peut être plastique, discursif, textuel. Le seul élément fédérateur et stable correspond en fait, comme l'indiquait Michael Riffaterre, au jugement de valeur porté par l'énonciateur. «Idée» ou «formule rabâchée » pour le Grand Larousse Universel, « thème » ou « mode d'expression " pour Le Grand Robert de la Langue Française, "formule de style, de sentiment, d'idée ou d'image " pour le Littré: le flottement terminologique des principaux dictionnaires modernes illustre le flou qui règne dans la définition de la notion, qui hésite entre contenu et expression, inventio et elocutio, phénomène stylistique et motif thématique, forme, structure, séquence ou syntagme. Ainsi, pour le Littré de 1863, le poncif, «formule de 
style, de sentiment, d'idée ou d'image [...] fanée par l'abus ", se définit moins par sa nature rhétorique que par son usage. Nous avons suivi cette interprétation, en privilégiant dans ce travail une définition souple de la notion: sa malléabilité nous a paru mieux à même de rendre compte de la diversité des phénomènes en jeu. Surtout, la péjoration intacte associée au mot nous permettait de suivre au plus près la démarche laforguienne, qui désigne sans cesse à l'attention du lecteur des références et des fragments textuels comme périmés, rebattus, topiques.

II. Les Moralités légendaires : «Vieux canevas, âmes du jour »a) Laforgue et le poncif

Laforgue traite d'une façon globale et complète des questions de stéréotypie: il les envisage aussi bien dans sa critique d'art, que dans ses poèmes et ses récits, dans leurs dimensions plastique, thématique et formelle, mais aussi esthétique et socioculturelle. Sa pratique scripturale s'enracine dans une ontologie pessimiste, fondée sur un constat désabusé : «nil sub sole novum ${ }^{17}$ ». Dès ses premiers écrits et de façon constante dans son œuvre, il doute des pouvoirs de renouvellement offerts à l'écrivain, sans pour autant jamais renoncer au travail de la langue. En particulier, il se montre conscient du fait que nul n'échappe aux poncifs, comme il l'affirme dans un essai consacré à son mentor, Paul Bourget :

Écrire! Mais ce penseur n'est-il pas convaincu qu'écrire une page, une phrase, la moins dogmatique, la plus flottante, la plus devenir et surtout la répandre, est une chose parfaitement présomptueuse, grossière, inintelligente, vieux-jeu [sic], un non-sens enfin? - Tout le monde peut écrire et il n'y a pas de littératures. Puis tout est déclamations, tout est d'avance un lamentable cliché18.

Héritier à la fois du spleen baudelairien et de l'ironie flaubertienne, Laforgue s'est montré très sensible à l'usure des discours et à la présence du déjà dit, qui hantent sa production poétique comme son recueil de nouvelles, les Moralités légendaires. Il manifeste ainsi la conviction de venir tardivement, alors que tout lui semble avoir été déjà dit, écrit, répété et ressassé :

le héraut des temps nouveaux, n'est-ce pas ce Bouvard-et-Pécuchet jetant aux générations ce glas des grands Don Quichottismes : 'En vérité, je vous le dis, il n'y a que copiasses et recopiasses !' ? Voilà le Lotus de la Bonne Loi. ${ }^{19}$

Laforgue n'en revendique pas moins son désir de se démarquer et de faire entendre une voix singulière dans le champ littéraire des années 1880 . Bien qu'il dresse pour son époque un constat d'universelle banalité, il s'engage dans l'écriture pour finalement parvenir à se démarquer dans le concert poétique et romanesque de la fin du dixneuvième siècle. Nous gageons que cette réussite tient justement pour une bonne part à l'usage critique et réflexif qu'il a su faire de matériaux à ses yeux éculés : il a osé les manipuler et les recycler, au lieu de tenter à tout prix de les éradiquer.

Dans le domaine poétique, son utilisation ludique et subversive des topoï génériques ouvre le poème à l'humour et surtout aux dissonances polyphoniques. D'une part, Laforgue pointe des topoï et des ficelles proprement poétiques, dénoncés comme les procédés convenus d'un certain savoir-faire pohétique; d'autre part, il introduit des clichés pour ainsi dire exogènes, empruntés à divers sociolectes et en particulier aux tours de la conversation familière, avec un effet contrastif certain. Le jeu avec ces divers clichés contribue à inventer une nouvelle manière poétique, à la fois désacralisée et déniaisée, déterminée à s'énoncer malgré les défaillances désormais assumées du Verbe. 

tout visée, qui touche les procédés romanesques. Saturée d'une ironie diffuse, chaque nouvelle s'apparente à un récit non-fiable, où le texte se distancie régulièrement de luimême. Le récit patine, s'enraye, s'embrouille, palinodie, laisse à tout propos entrevoir le caractère conventionnel des modes de production fictionnelle. L'illusion référentielle est sans cesse parasitée par un narrateur trouble-fête, qui remplit son rôle de manière volontairement empruntée et inopportune. Les cibles de l'ironie ne sont plus un Parnasse jugé essoufflé ni une Muse romantique frelatée, mais essentiellement les modèles du roman, notamment réaliste, ainsi que la tentation du légendaire, qui commence alors à travailler l'époque. Plus généralement, c'est toute la tradition du récit occidental qui se voit ici remise en cause et interrogée dans ses fondements. Dans la lignée de Jacques le Fataliste et de Tristram Shandy, mais aussi des Chants de Maldoror, un narrateur facétieux met sans arrêt à nu les codes, procédés et artifices de la narration fictionnelle " classique ». C'est cette attaque en règle contre ce que Laforgue perçoit comme poncifs narratifs que nous nous proposons d'étudier de près.

b) Sachets éventés

19 Le recueil des Moralités légendaires rassemble six récits composés par Laforgue autour de 1885, à savoir: Hamlet, ou les suites de la piété filiale; Le Miracle des roses; Lohengrin, fils de Parsifal; Salomé ; Persée et Andromède, ou le plus heureux des trois et Pan et la Syrinx, ou l'invention de la flûte à sept tuyaux. L'auteur manifeste la volonté de remettre au goût du jour des structures narratives usées, pour les adapter à la sensibilité et à l'esthétique contemporaines. Le caractère " poncif » des six récits fait d'emblée partie du projet d'écriture global. Le mythe est avant tout envisagé ici comme une vieille histoire périmée, largement colportée et sans surprise. En témoigne la série de titres projetés pour le recueil des Moralités, soumis à Gustave Kahn dans une lettre de juin 1886 :

Comment intituler mes nouvelles?

« Vieux canevas, âmes du jour »?

« Moralités légendaires "?

« Fabliaux d'antan "?

"Sachets éventés ${ }^{20}$ "?

L'image du "sachet éventé » est révélatrice: elle évoque un produit altéré par le contact avec l'air, qui a tourné ou perdu son odeur, mais renvoie aussi au secret ébruité. Les "récits éventés " que représentent mythes et légendes correspondent parfaitement à la définition de poncifs : ce sont des formules passées, qui ont perdu leur saveur à force d'être exposées au grand jour et diffusées dans l'air du temps. Nous constatons que le terme de mythe, absent de la liste, est concurrencé par les paradigmes voisins de la légende, du conte et de la fable. Les Moralités vont en fait emprunter à plusieurs traditions narratives: outre celles que nous venons de citer, elles puisent aussi majoritairement dans la nouvelle et la tradition romanesque, du Grand Siècle aux formules modernes (réalistes, voire naturalistes), sans oublier des incursions vers le poème en prose, le théâtre, l'opéra, le monologue de cabaret... La structure mythique, si elle subsiste, éclate sous la poussée de discours et de pratiques génériques hétérogènes : le récit s'apparente à un vaste pot-pourri culturel, qui liquide à tour de bras les conventions narratives reconnues, des plus anciennes (comme le mythe, le conte, la chronique, l'hagiographie) aux plus contemporaines (comme la focalisation omnisciente balzacienne ou le néo-merveilleux symboliste). L'écrivain se situe bien dans une perspective de « distorsion littéraire du mythe ${ }^{21}$ », pour reprendre l'heureuse

Cahiers de Narratologie, 17 | 2009 
expression de Jean-Pierre Vernant. Plus généralement, il bouscule nos certitudes en attaquant frontalement les codes culturels qui président habituellement à la composition d'un récit fictionnel.

Les mythes et les canevas légendaires, qui servent de support aux Moralités légendaires, deviennent les cibles d'une parodie diffuse et multifocale. La vaste opération critique à laquelle se livre Laforgue a pour premier effet de les désigner comme des récits banalisés, en un mot des poncifs, qui appellent une inspiration d'un nouveau genre. Dans Salammbô, Flaubert cherchait, selon ses propres termes, à « tirer des effets neufs du tourlourou antique ${ }^{22} »$. On peut dire que Laforgue affiche la même intention, mais emprunte pour cela des voies bien différentes, fondées sur l'humour et la réécriture de récits qu'il aura au préalable démembrés et évidés. Il prodigue ainsi à Kahn le conseil de « ne prendre [...] les monochromes dieux grecs que pour les mener à la foire ${ }^{23} »$. Pour Laforgue, l'inspiration antique est désormais bien tarie, à moins de passer par la voie oblique de la parodie. Pour renouveler ces « airs connus » que représentent les mythes, l'auteur s'attache à les dépayser et à les disséquer : il en démonte les mécanismes et opère de multiples croisements fantaisistes, non seulement entre plusieurs mythes et entre de multiples hypotextes, mais entre mythe et narration moderne. C'est à ce prix que le poncif, pointé du doigt et mis en pièces, redevient un support d'invention et de créativité narratives.

En même temps qu'il les réagence et les réinterprète, Laforgue se plait à signaler le caractère poncif de l'intrigue, des lieux ou des personnages, pour instaurer avec son lecteur une complicité d'initiés. La symbolique des lieux est à cet égard souvent révélatrice : les récits se déploient à partir d'un espace stagnant, clos ou franchement chromo, qui indique l'aliénation liminaire du texte au poncif.

c) Lieux topiques : « (Ah! connu, l'décor !)»

23 Cette interprétation ${ }^{24}$ n'est pas exclusive, mais vient plutôt se superposer à d'autres. Si les paysages de Hamlet sont faits d'enlisement et de miasmes, c'est bien sûr d'abord parce qu' «il y a quelque chose de pourri au royaume de Danemark» : la corruption morale règne sur le trône, sans compter qu'une culpabilité latente ronge le justicier velléitaire. Ces mornes sites annoncent aussi les représentations, chères aux symbolistes et aux décadents, de l'eau dormante, comme on en trouvera dans Bruges-la-morte de Rodenbach ou dans le conte Narkiss ${ }^{25}$ de Jean Lorrain, qui allie crûment eau et pourriture. Le " coin d'eau » sur lequel donne la tour du château où vit Hamlet "est bien le miroir de l'infortuné prince » et fonctionne avant tout dans un rapport de spécularité narcissique avec le personnage, mais la "pauvre anse stagnante" reflète également le figement du mythe, ancré dans une sorte de croupissoir: "Voilà quel fut le point de départ de ses méditations et de ses aberrations ${ }^{26}$ ", affirme le narrateur dans l'incipit en parlant de l'eau familière à Hamlet. Celle-ci fait ensuite l'objet de descriptions fouillées, artistement composées :

Ce coin de parc est le cloaque où l'on jette les détritus des serres, les décatis bouquets des galas éphémères. [...]

L'assise de la tour où le jeune et infortuné prince s'est décidément arrangé pour vivre, croupit au bord d'une anse stagnante où le Sund s'arrange aussi pour envoyer moisir le moins clair de l'écume d'épave de ses quotidiens et impersonnels travaux ${ }^{27}$.

24 "[C]loaque ", croupissement, écume sale, "épave »: le décor morbide renvoie aux "saletés de la vie ${ }^{28}$ ", mais aussi à l'usure de l'univers légendaire, où s'accumulent les 
bouquets fanés. Le narrateur s'attarde à décrire le " coin d'eau mûre » symbolique, en insistant sur la figure antipoétique du crapaud, chargée de connotations culturelles ${ }^{29}$ :

Du fond vaseux de paquets d'herbages, là, montent, aux pluvieux crépuscules, vers la fenêtre de ce prince si humain, les chœurs d'antiques ménages de crapauds, râles glaireux expectorés par de catarrheux vieillards dont un rien de variation atmosphérique dérange les rhumatismes ou les gluantes pontes ${ }^{30}$.

La sérénade se transforme en expectoration poussive, les "chœurs antiques" des batraciens semblent figurer un discours à bout de souffle, un chant dérisoire et repoussant. Qu'il s'agisse des mythes et légendes, de la tragédie antique, de la poésie, ou encore du classicisme, il est tentant de penser que les crapauds catarrheux fonctionnent comme le signe d'un discours littéraire périmé, qui se trouve moqué sans être pour autant clairement identifiable ${ }^{31}$. L'accumulation de tels détails au seuil de la moralité ne peut laisser indifférent : le récit semble devoir s'arracher à un enlisement initial qui, au niveau du langage, n'est autre qu'un fonds culturel rebattu. Le lexique de l'usure et de la décomposition est d'ailleurs appliqué un peu plus loin aux lectures du prince : un « fumier de livres ${ }^{32}$ » s'accumule sur la table de Hamlet parmi d'autres objets mis au rebut. Tout se passe donc comme si le caractère «moribond» ou faisandé du mythe était d'abord signalé par un décor symbolique de nature indicielle, éminemment décadent dans ses caractéristiques descriptives et stylistiques.

De même, dans Persée et Andromède, le narrateur fait tourner en rond personnages et lecteurs sur une île inhospitalière, "patrie monotone et imméritée ${ }^{33}$ " où règne l'ennui, avant que le récit ne s'émancipe du vase clos de la légende. La mer, " qui est à tous ${ }^{34}$ " dans Hamlet et "appartient à tout le monde ${ }^{35}$ » dans Les deux Pigeons, nouvelle finalement écartée du recueil, suscite des descriptions appuyées. Le narrateur, qui adopte ici le point de vue subjectif d'Andromède, ressasse le mouvement régulier des vagues, « le mécanisme des flots, des flots naissant et mourant à perte de vue ${ }^{36}$ » :

L'île seule, en jaunes grises dunes; sous des ciels migrateurs; et puis, partout, la mer bornant la vue, les cris et l'espérance et la mélancolie.

La mer! de quelque côté qu'on la surveille, des heures et des heures, à quelque mouvement qu'on la surprenne : toujours elle-même, jamais en défaut [...]. La mer, toujours la mer sans un instant de défaillance ${ }^{37}$ !

Voici encore la description maritime qui campe ce décor insulaire :

La mer, cet après-midi, est quelconque, vert-sombre à perte de vue ; moutonnement à perte de vue d'innombrables écumes si blanches s'allumant, s'éteignant, se rallumant comme un innombrable troupeau de brebis qui nagent, et se noient, et reparaissent, et jamais n'arrivent, et se laisseront surprendre par la nuit. Et par làdessus, les ébats des quatre vents, leurs ébats pour l'amour de l'art, pour le plaisir de tuer cette après-midi à fouetter, en poussière qui s'irisent, les crêtes d'écumes. Oh! qu'un rayon de soleil passe et c'est sur le dos des vagues la caresse d'un arc-enciel comme une riche dorade qui a monté un instant et aussitôt replonge, stupidement méfiante.

Et c'est tout. O patrie imméritée et monotone ${ }^{38}$ !...

La nature déceptive du paysage textuel est explicitée par la courte phrase présentative : «Et c'est tout ». La mer est " quelconque », l'île, « monotone ». Le déferlement régulier des vagues, le jeu sans but des vents, l'image du troupeau de mouton, tout annonce une promesse de répétition, source d'ennui, tandis que le chatoiement de la dorade suggère une illusion, un jeu de dupe : ce qui scintille un instant disparaît sans laisser de trace, frustrant l'observateur qui n'a rien pu saisir qu'un reflet diapré. Là encore, la description initiale du cadre fictionnel semble prévenir le lecteur qu'il est en terra 
cognita, lieu d'élection de l'ennui et du déjà advenu, bref, du poncif. Comme dans Hamlet, le récit s'ouvre sur une eau monotone, sur laquelle l'héroïne projette sa lassitude existentielle. Propriété commune qui barre l'horizon de son flux et reflux continuel, la mer est le principal obstacle à surmonter pour qu'advienne enfin quelque chose de neuf. L'eau qui encercle la terre, la mer qui stagne dans une anse putride ou qui dévide l'écheveau sans fin de ses rouleaux, expriment à la fois une hantise et une fascination pour l'enlisement dans la réitération. Ces marines symboliques convoquent au premier chef des représentations ontologiques, mais il paraît judicieux de leur donner aussi un équivalent sur le plan du dire : chaque moralité se construit sur un fonds culturel commun usé et figé, qu'il s'agit de revivifier grâce à un discours résolument moderne, à la fois novateur et dégagé de la tradition narrative.

Cette approche est également valable pour Le Miracle des roses, où le cadre de la ville d'eaux est lui aussi assimilé à un poncif pictural, toutefois plus riant :

Et puis des collines, des sites de chromo retouchés de donjons romantiques et de cottages à croquer ${ }^{39}$.

Remarquons au passage que ces collines forment encore une fois un "cercle » fermé enserrant la fiction dans une sorte de huis clos élargi. Elles désignent surtout l'espace romanesque comme un vaste cliché: le narrateur ne se privera d'ailleurs pas d'y retourner les codes narratifs comme autant de gants usés, refusant par exemple de livrer certains éléments énigmatiques de l'intrigue pourtant ostensiblement soulignés, comme s'ils allaient faire par la suite l'objet d'une élucidation.

Le cadre chromo du Miracle des roses trouve son pendant dans la moralité Pan et la Syrinx, qui s'ouvre à son tour sur un paysage poncif, celui d'un locus amoenus verdoyant. Le narrateur accentue à plaisir ce qu'il présente délibérément comme un cliché :

Sur son galoubet matinal, Pan se plaint, Pan donne cours à des doléances très personnelles, aux échos de la Vallée-du-Gazon-Diapré, en Arcadie. Tout le monde a passé par une belle matinée d'été dans une vallée folâtrement merveilleuse, tout le monde dira : «Je sais ce que c'est ${ }^{40}$.

En insistant sur le caractère topique du décor de la moralité, le narrateur pointe d'emblée la banalité de la promenade littéraire. Malgré les apparences, l'incipit renvoie moins à l'expérience concrète du lecteur («Tout le monde a passé »...) qu'à son expérience livresque (tout le monde a déjà lu et relu des descriptions semblables). De fait, les effets de reconnaissance vont jouer à plein dans la nouvelle. L'un des arrêts des personnages n'a d'autre but, par exemple, que de mettre en valeur une surprenante ekphrasis, qui prend la forme d'une citation picturale. Tour à tour, Syrinx et Pan s'immobilisent devant un tombeau tout droit venu des Bergers d'Arcadie de Poussin :

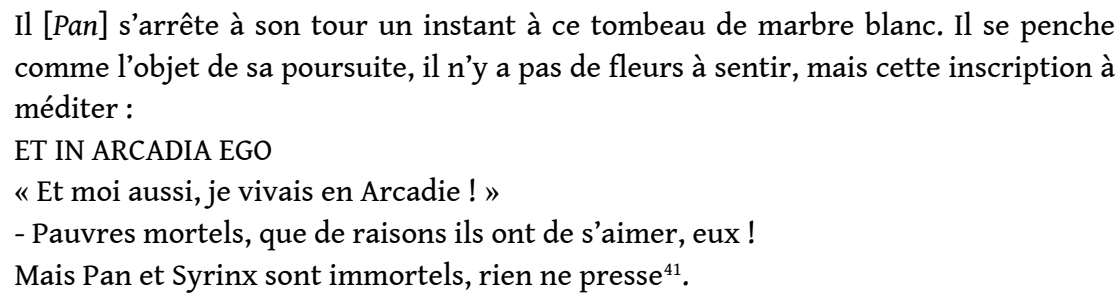

Laforgue connaissait le tableau, exposé au Louvre, où il a fait de fréquentes visites. On sait que les personnages y déchiffrent la célèbre épitaphe "Et in Arcadia ego ", qui sert aussi de sous-titre à l'œuvre de Poussin. Laforgue prend soin de placer sur le chemin de Pan et de Syrinx le fameux " tombeau de marbre blanc » afin qu'ils y lisent à leur tour la mélancolique maxime. La poursuite légendaire se transforme ainsi en traversée du 
poncif pictural. Ce statut ne concerne pas nécessairement la toile de Poussin, mais plutôt la reprise volontairement grossière et voyante qui en est proposée dans la moralité. La solennité sentencieuse de la scène est soulignée par la mise en valeur à outrance de l'inscription, qui se détache en lettres capitales, conformément à la tradition typographique, mais se voit aussi redoublée par la traduction et fait en sus l'objet de deux commentaires, l'un émanant du personnage et l'autre, du narrateur. Dans le même temps, le cérémonieux sentimental de l'épisode est aussitôt dégonflé : "Pan et Syrinx sont immortels", ils ne sont pas concernés par ce memento mori, qui apparaît donc rétrospectivement comme un ex cursus parfaitement gratuit et même intempestif.

Il est intéressant de remarquer à ce propos combien le récit laforguien, qui s'autodésigne comme épuisé, passe toujours par la médiatisation d'autres œuvres, qu'il s'agisse des Métamorphoses d'Ovide, de l'Iliade homérique, du Hamlet shakespearien, du Lohengrin wagnérien, ou encore de l'Hérodias de Flaubert. Le mythe suspend ici sa dimension anthropologique au profit d'une définition toute littéraire du terme. La réécriture qu'il suscite donne à l'auteur l'occasion de s'inscrire dans une filiation esthétique et d'apposer son empreinte personnelle sur un canevas connu de tous. La reprise se fait essentiellement par le biais d'une réécriture, souvent parodique, et éveille chez le lecteur une impression de " déjà lu », avec un effet de palimpseste.

Outre les lieux « communs » qui servent de cadre spatial à chaque moralité, des rappels jalonnent sans cesse le texte pour pointer le caractère familier d'une histoire déjà connue du destinataire. En voici un exemple caractéristique, tiré de Pan et la Syrinx :

Et la légendaire poursuite de la nymphe Syrinx par le dieu Pan dans l'Arcadie commence. Oh, quelle aventure ${ }^{42} ! . .$.

Le commentaire narratorial prend une résonance antiphrastique : les trois points de suspension laissent présager un récit plein de rebondissements; or, il ne réserve ni surprise, ni aventure, au sens étymologique du terme, puisque la trame des événements à venir est depuis longtemps fixée, et ne doit donc rien au hasard. Le narrateur s'appesantit à satiété sur les données les plus consensuelles du mythe :

o longue journée légendaire, tu es loin, tu ne reviendras plus !... Cela se passait en Arcadie avant la venue des Pélasges ${ }^{43}$.

Et la légendaire poursuite de la nymphe Syrinx par le dieu Pan continue dans l'accablante après-midi qui finira bien par se fondre en $\operatorname{soir}^{44} \ldots$

De même que la succession des moments de la journée est immuable, l'histoire suit son cours vers une fin attendue. En qualifiant de "légendaire » le récit et ses épisodes, le narrateur les dénude : le mythe n'est pas censé révéler son caractère imaginaire, ni le merveilleux s'avouer tel. Comme il le fait continuellement dans les Moralités, Laforgue rompt sciemment l'illusion référentielle, frustrant ainsi volontairement le lecteur du plaisir de la fiction. Nous savons que cette illusion repose sur la convention d'un pacte implicite: le narrateur feint de rapporter des événements, généralement présentés comme vrais; le lecteur, en retour, fait mine de le croire et d'adhérer à la vérité référentielle et psychologique du récit, aussi merveilleux fût-il. Si le premier faillit à son rôle, le lecteur peut s'estimer dupé et lésé ; surtout, ses repères sont brouillés et il se trouve décontenancé par un discours qu'il ne sait plus par quel bout aborder. Contrarié, le plaisir de la lecture se déplace alors vers une connivence d'initiés: en exhibant les mécanismes de la fiction et du récit, l'auteur cherche à s'attirer la sympathie d'un public averti, capable de goûter la manœuvre, autant qu'il se réjouit d'agacer et de dérouter la masse des Béotiens dans leurs habitudes et leurs attentes. Ce 
qui nous paraît, en effet, le plus digne d'être retenu ici, c'est la complicité culturelle et critique que la manipulation du poncif permet d'instaurer entre l'auteur et son lecteur. La dimension de la réception est de toute façon constitutive du concept. De multiples stratégies sont mises en œuvre dans les textes pour dépister le destinataire et dérouter ses attentes. En modifiant légèrement une formule toute faite, en utilisant tel ou tel thème compassé à contretemps et hors de propos, Laforgue réintroduit la surprise dans les structures et les motifs qui lui paraissent banalisés. Les références culturelles communes, à demi travesties, initient alors de subtils processus de reconnaissance et de défamiliarisation. Le lecteur est ainsi convié à savourer l'inventivité verbale d'une écriture qui élabore dans le même temps une réflexion métapoétique poussée. Le jeu sur le Code est mis au premier plan dans la relation entre destinateur et récepteur, au détriment d'autres protocoles de lecture plus conventionnels, dont fait partie l'illusion référentielle. Dans les Moralités légendaires, la manipulation des poncifs romanesques nous semble à cet égard relever d'une sorte d'éducation du lecteur, qui passe par la frustration de son désir primitif. Lui est en effet refusée la forme de jouissance qu'il est accoutumé à retirer des textes fictionnels. Une analogie avec la castration, au sens psychanalytique du terme, n'est peut-être pas infondée. En s'opposant à son désir de consommation fictionnelle, de nature orale, le narrateur initie le lecteur à d'autres formes de jouissance textuelle, plus matures, qui l'associent étroitement à la manipulation de l'objet-récit. L'analogie s'arrête là : il s'agit de dépasser un stade pour accéder à une autre forme de la relation au texte. Tous les lecteurs ne s'y retrouveront pas : ils ne seront pas tous prêts à franchir ce pas, c'est-à-dire à renoncer au plaisir du faux-semblant que procure l'illusion référentielle, sans cesse niée et bafouée. La rupture des habitudes réceptives est en tout cas au fondement de la composition des Moralités légendaires.

d) Guitares

Laforgue entend en effet déconstruire par la parodie tout ce qui fonde les certitudes culturelles et les habitudes narratives occidentales: entreprise ambitieuse, mais qu'il mène à merveille, avec une verve inégalée. Un narrateur intempestif s'attache à mettre à nu les procédés d'écriture, afin de mettre en évidence « la vérité textuelle du récit ${ }^{45}$ ». L'auteur des Moralités pourrait reprendre à son compte le portrait qu'il dresse de Corbière :

- à chaque sortie il avertit : vous savez! me prenez pas au sérieux, tout ça c'est fait

de chic, je pose. Je vais même vous expliquer comment ça se fabrique ${ }^{46}$.

Peu fiable, désinvolte et ironique, le narrateur ${ }^{47}$ se plaît à modifier à son gré les données d'une histoire connue ${ }^{48}$, met l'accent sur l'aspect ludique de la composition et sur son caractère artificiel. Il ne cherche pas à dissimuler la facticité du décor ou des héros ${ }^{49}$, mais insiste au contraire sur les praticables et les trappes du récit, souligne ici un "phare d'opéra comique ${ }^{50}$ ", là une "lune de gala ${ }^{51}$ ", pointe ostensiblement les emprunts théatraux ${ }^{52}$. Dans la multiplication des incidentes, le narrateur jaillit sans cesse comme un diable de sa boîte. Au sein d'un texte saturé d'effets sonores et rhétoriques, il appose partout sa marque, dans les exclamatives et les questions intempestives, les longs adverbes de manière dispensés sans compter, les adjectifs incongrus, souvent antéposés, en imitation de l'écriture artiste. Aucune phrase ne cherche la neutralité de la forme et du sens, toutes sollicitent le lecteur, lui indiquent des directions contradictoires. Dans chaque nouvelle s'impose ainsi la présence une 
voix particulière et insistante, qui affiche une désinvolture provocante, et se livre à la déconstruction du récit.

En particulier, la réécriture du mythe est généralement soulignée avec une insistance volontairement pesante: à chaque instant, le narrateur vient nous rappeler que l'histoire qu'il nous conte nous est parfaitement familière. Elle est même à ses yeux si consensuelle, qu'il se permet d'omettre certains épisodes, le texte nous renvoyant alors implicitement à la tradition établie. Dans Lohengrin, fils de Parsifal, les spectateurs concluent de leur observation d'Elsa :

Et l'on vit bien qu'Elsa ne se donnait même pas la peine de lancer un clin d'œil au hasard de cette foule, d'où elle n'attendait donc nul Chevalier, c'est clair ${ }^{53}$.

41 La mention prématurée de ce "Chevalier", dont Elsa n'a pas encore évoqué le rêve prémonitoire, ne peut en conséquence renvoyer qu'à l'hypotexte wagnérien. Son irruption éventuelle est même désormais intégrée à un cérémonial, comme le rappelle le «Confesseur d'Hécate»:

Maintenant, veuve Elsa, contemplez une dernière fois la Déesse ; car, selon le rite, si, sur trois sommations, votre fiancé ne se présente pas pour vous assumer, on va brûler vos beaux yeux ${ }^{54}[\ldots]$

Rien d'étonnant à ce que l'attente du champion, d'avance désigné comme "fiancé ", soit ici ritualisée : elle ne fait que répéter et rejouer la scène fondatrice issue de l'opéra wagnérien. Lorsque paraît Lohengrin, il est salué par les exclamations : «Le voici ! Que c'est Lui !» On ne sait trop s'il faut les attribuer au narrateur où s'il s'agit de style indirect libre traduisant soit l'admiration de la foule, soit la réaction de la seule Elsa. L'utilisation déictique du pronom "Lui », qui suppose généralement une interprétation anaphorique, montre en tout cas que l'arrivée de Lohengrin fusionne avec l'espérance de la jeune fille : il est bien le type du « Prince Charmant ${ }^{55}$ » entrevu en songe, celui de l'amant idéal et du chevalier sauveur, comme le confirme la majuscule. L'attente satisfaite des spectateurs repose sur la conformité des événements à la Norme : Lohengrin surgit d'un horizon qui n'est autre qu'un horizon d'attente conventionnel. Le récit tend donc à revêtir une signification métatextuelle : l'apparition attendue du héros ne coïncide pas seulement avec les rêves d'Elsa, mais surtout avec les données de l'opéra wagnérien, que sa venue accomplit. Le lecteur complice est sans cesse invité à identifier les traces de l'œuvre antérieure sous le texte de la moralité : une bonne part de l'action se déroule en référence à une autre intrigue connue et explicitement rappelée. La reconnaissance est favorisée et provoquée : l'auteur ne cherche pas à faire oublier qu'il brode sur une intrigue connue, mais vient au contraire rappeler ostensiblement qu'il «sert du réchauffé" à ses lecteurs, si l'on nous permet l'expression. Ce faisant, il sacrifie à dessein la vraisemblance de son histoire à la mise en évidence de sa topicité. Nous avons vu par exemple que Laforgue transgressait dès le départ le pacte dramatique qui imposait chez Wagner de tenir secret le nom du héros. Il s'agit certes là d'une irrévérence parodique flagrante à l'égard de la légende imaginée par le compositeur ${ }^{56}$, mais nous pouvons aller plus loin. Par cet accroc à Wagner, l'écrivain signale clairement le caractère postérieur de sa propre œuvre; son Lohengrin vient après le célèbre opéra: il est donc inutile de chercher à dissimuler l'identité illustre du héros, déjà éclaircie à la fin de la pièce... Les ressorts dramatiques ayant déjà servi auprès du public, Laforgue déplace le centre d'intérêt de la moralité vers d'autres effets de reconnaissance où pourra s'établir une complicité d'un type différent entre auteur et lecteur, narrateur et narrataire. On peut comparer le surgissement de Lohengrin à celui de Persée : tous deux font une entrée remarquée sur une monture 
céleste magique. Dans l'un et l'autre cas, le héros est d'emblée identifié : Lohengrin est le « Lui » attendu, et montre aussitôt ses papiers ${ }^{57}$; quant à Persée, il est nommé avant même de s'être présenté (comme il le fait pourtant chez Ovide, en bon héros et futur gendre, devant les parents d'Andromède) :

Allons, silence et horizon prêt pour la mortuaire Lune, - quand ! Oh, bénis soient les dieux qui envoient, juste au moment voulu, un troisième personnage.

Il arrive comme une fusée, le héros de diamant sur un Pégase de neige dont les ailes teintes de couchants frémissent, et nettement réfléchi dans l'immense miroir mélancolique de l'Atlantique des beaux soirs !...

Plus de doute, c'est Persée ${ }^{58}$ !

Dans les Métamorphoses, le fils de Danaé surgit lors d'un climax, quelques instants à peine avant l'attaque du monstre marin. Loin d'être motivée par l'imminence du danger, l'arrivée du Persée laforguien « juste au moment voulu » vient à point, non pas parce que le Monstre est sur le point de dévorer son innocente proie, mais plutôt parce que la morosité d'Andromède, qui dépérit d'ennui sur son île, a atteint son comble... La venue de Persée est simplement perçue comme un évènement obligé de l'histoire ; elle n'est plus justifiée par la nécessité de l'exploit héroïque ${ }^{59}$. De fait, la mise à mort du Monstre sera décrite un peu plus loin comme un meurtre lâche et sadique, totalement démotivé. Tout se passe comme si le seul respect de la légende (ce qui est donné à lire, et donc ce qui doit être écrit par l'auteur pour se conformer à la tradition légendaire) suffisait à justifier l'action, ce qui, en retour, fait ressentir cette fidélité comme absurde. L'insistance avec laquelle est rappelé le lien au texte source décrédibilise le récit laforguien sur le plan référentiel : le texte ne renvoie pas à un univers imaginaire propre, mais ouvre à l'infini sur d'autres textes, comme dans un palais des glaces. Ainsi, comme c'est également le cas dans Lohengrin, fils de Parsifal, une exclamation de reconnaissance émanant du narrateur accompagne l'entrée en scène du personnage mythologique : «Plus de doute, c'est Persée !» Son nom n'ayant jamais été prononcé auparavant, il faut bien en conclure que le texte renvoie le lecteur hors de son système référentiel immédiat, c'est-à-dire, en l'occurrence, au célèbre canevas ovidien dont il s'inspire. Cette impression est confirmée par le portrait en armes que le narrateur dresse du héros :

Persée est coiffé du casque de Pluton qui rend invisible, il a les ailes et les talonnières de Mercure et le divin bouclier de Minerve, à sa ceinture ballotte la tête de la Gorgone Méduse dont la seule vue changea en montagne le géant Atlas, comme on sait, et son hippogriffe est le Pégase que montait Bellerophon quand il tua la Chimère. Ce jeune héros a l'air fameusement sûr de son affaire ${ }^{60}$.

Dans ce contexte parodique, l'incise "comme on sait " n'est pas là pour emporter l'adhésion d'un auditoire et le réunir dans le plaisir d'une culture partagée : il s'agit de mettre l'accent sur le poncif, en faisant l'aveu du caractère platement conventionnel d'une description conforme aux attendus de l'épisode légendaire. D'une manière générale, l'histoire est censée se dérouler sans surprise, et Laforgue souligne à plaisir cette absence de suspense, en multipliant les allusions métatextuelles. Voici par exemple en quels termes le Dragon laforguien commente l'arrivée de son ennemi :

Et de grosses larmes viennent aux cils du Monstre, comme des girandoles à des balustrades. Il parle d'une voix que nous ne lui connaissions pas du tout :

- Andromède, ô noble Andromède, rassure-toi, c'est Persée. C'est Persée, fils de Danaé d'Argos et de Jupiter changé en pluie d'or. Il va me tuer et t'emmener.

- Mais non, il ne te tuera pas!

- Il me tuera.

- Il ne te tuera pas s'il m'aime. 
- Il ne peut t'emmener qu'en me tuant.

- Mais non, on s'entendra. On s'entend toujours. Je vous arrangerai ça ${ }^{61}$. rapproche, d'ailleurs, de la comédie bourgeoise ${ }^{62}$, le Monstre révèle laconiquement toutes les étapes d'une intrigue prédéfinie, aussi immuable qu'un destin. Il annonce une trame connue d'avance par le lecteur car, si «nous ne [...] connaissions pas du tout " une telle voix au Monstre, nous sommes en revanche parfaitement au fait des événements énumérés dans son discours, qui est finalement moins prédiction que récapitulation... Si Laforgue feint de respecter scrupuleusement la fable ovidienne, dont il rappelle ostensiblement les grandes lignes, c'est aussi pour mieux en bouleverser le dénouement. Il prend Andromède au mot et choisit d'" arranger ça » à sa manière, ce qui vaudra a posteriori au conteur intradiégétique les protestations de son auditrice princière. L'insistance sur les aspects connus de l'histoire prend rétrospectivement une dimension ironique, puisque Laforgue ne les a mis en avant que pour rendre la transgression plus ostensible. Il joue avec les matériaux éculés que constituent à ses yeux mythes, contes et légendes, en multipliant les allusions métatextuelles. «[C]'est une vieille histoire ", affirme Hamlet à propos des rapports sociaux, en se désignant luimême comme un "parasite féodal ", avant de conclure proverbialement: "tout est bien qui n'a pas de fin ${ }^{63}$ ». Si les propos du prince se rapportent d'abord à l'existence, leur présence n'est cependant pas anodine dans un récit qui prolonge l'argument shakespearien, maintes fois sollicité au point de s'être constitué en véritable mythe littéraire. L'aphorisme laforguien est d'ailleurs calqué sur le proverbe anglais All's well that ends well (« Tout est bien qui finit bien »), justement choisi par Shakespeare comme titre pour l'une de ses comédies. La "vieille histoire » désigne donc aussi de manière sous-jacente celle de la célèbre pièce, qui a suscité elle aussi des reprises sans fin.

Ainsi, partout dans les Moralités s'affirme cette manie de mettre en évidence le poncif, au point de contrarier toute tentative de lecture innocente des textes. Les stratégies parodiques et le dénudement des procédés narratifs perturbent l'usage et la réception habituels des formes et des contenus figés. Comme le poncif est partout apparent, partout souligné, tout stéréotype potentiel éveille le doute dans ces textes : en raison de la parodie diffuse qui y règne, le lecteur hésite à lui attribuer un statut de forme «pleine» ou d'énoncé «naturel», au sens barthésien des termes, tant Laforgue a introduit de jeu dans le discours.

e) Déconstruction narrative : «On voit les fils de fer et les trucs ${ }^{64}$.»

Revenons à la nouvelle Pan et la Syrinx, que nous évoquions plus haut. Outre le fait qu'il insiste sur une filiation intertextuelle, le rappel régulier de la « légendaire poursuite » a aussi une autre fonction : sa répétition tend à suggérer que le mythe tourne court et qu'il s'y passe au fond bien peu de choses. Chez Ovide, sa narration occupe d'ailleurs une place très restreinte dans le livre premier des Métamorphoses. Chargé par Jupiter de tuer Argus, Mercure endort le monstre en jouant du pipeau et en lui narrant l'origine de l'instrument. Le narrateur complète rapidement pour le lecteur une histoire inachevée dans la bouche du dieu, puisque Argus s'est en fait assoupi avant d'entendre la fin :

Comme elle [Syrinx] revenait des hauteurs du Lycée, Pan la voit, et, la tête hérissée d'une couronne de pin, il lui adresse ces paroles... Il restait à Mercure à rapporter ces paroles, à raconter la fuite de la nymphe, dédaigneuse des prières de Pan, jusqu'à ce qu'elle atteignît le Ladon, dont les eaux coulent sur son lit de sable ; comment là, les ondes arrêtant sa course, elle avait prié les nymphes des eaux, ses sœurs, de la métamorphoser ; [...] 
Comme il s'apprêtait à ce récit, le dieu né sur le Cyllène vit que tous les yeux

d'Argus avaient succombé au sommeil, fermant leurs paupières ${ }^{65}$.

d'Hermès, pour lequel le discours n'avait qu'une fonction performative: tromper la vigilance de son adversaire. Ce faisant, le poète abrège l'histoire et en bouscule les épisodes ; il omet en particulier de rapporter les « paroles » de Pan à Syrinx. À son tour, Laforgue va compléter les non-dits du texte : la moralité prend clairement place dans les interstices et les blancs du récit ovidien, qu'elle s'efforce de combler. Elle va ainsi l'étoffer considérablement. Le récit enchâssé, qui tient en quelques vers chez Ovide, constitue donc comme l'argument de la moralité laforguienne. Cette augmentation du volume textuel est logique. Bien souvent, on est frappé par la brièveté du récit mythique dans ses premières manifestations écrites ${ }^{66}$ : les réécritures successives se situent généralement dans une démarche d'amplification de leur hypotexte. Laforgue développe le canevas ovidien, entre dans les détails de la poursuite et des dialogues, qu'Ovide ne faisait qu'esquisser à grands traits, mais, dans le même temps, il émaille aussi sa nouvelle de renvois ostensibles aux linéaments simples de l'intrigue, comme pour rendre bien visible l'hypertrophie qu'il fait subir au texte des Métamorphoses. Laforgue tire ainsi sur la corde du mythe, le dilate jusqu'à le dénaturer. «[A]lpha, oméga, c'est bien élastique ${ }^{67} "$, finit par conclure le tétrarque de l'oracle spectaculaire qui a accompagné sa naissance. Cette phrase, qui exprime le pragmatisme du tétrarque face au miraculeux, s'applique parfaitement au traitement laforguien du mythe : il se fonde non seulement sur la parodie ${ }^{68}$, mais sur la distorsion de la structure narrative, rendue si «élastique » qu'il est possible d'y fourrer tout un bric-à-brac étranger à l'histoire initiale.

Restés apparents, les plus gros fils de la trame ovidienne ainsi distendue sont là pour témoigner des vestiges de l'hypotexte parmi les addenda qui les entourent. Leur présence souligne aussi combien l'intrigue de départ est dépouillée, sommaire pourraiton dire. En prolongeant artificiellement la course des personnages, Laforgue s'amuse à temporiser et à différer sans cesse l'achèvement de la nouvelle, comme le montre la succession d'interruptions et de reprises qui structurent la poursuite :

[Issue de la première rencontre]

Syrinx pousse un strident éclat de rire de Walkyrie et, oubliant Pan, la voilà qui prend sa course, oh, jeune course bondissante! par la prairie et la vallée, dans la belle matinée!

[...] Pan aspire le grand air qui est à tous et s'élance à la poursuite de la précieuse fugitive ! En chasse ! en chasse ${ }^{69}$ !

[Syrinx découvre qu'elle a un poursuivant]

Elle est déjà loin. Elle se retourne et se voit poursuivie. Elle s'arrête un instant et fait front; puis reprend son galop, éperdue ${ }^{70}$ !

[Fin de l'épisode de l'« armistice » où Syrinx, sur une éminence, se trouvait hors de portée]

- En chasse ! en chasse ! clame Syrinx qui, divinisée à cet appel, a sauté sur ses pieds et reprend son galop vers la journée ! en poussant des clameurs de Walkyrie!

Hoyotoho!

Heiaha!

Hahei ! Heiaho! Hoyohei !

C'est à recommencer ${ }^{71}$.

[Pause à l'initiative de Pan]

Et pour laisser sa fiancée respirer un peu, Pan, arrivé au haut d'un coteau dominant une nouvelle plaine, fait halte. La fiancée se retourne un instant, s'étonne. En a-t-il assez ? Veut-il renoncer à ce jeu ? Elle n'a pas confiance, elle repart ! Hoyotoho ${ }^{72}$ ! 
[Épisode du tombeau]

Syrinx s'y arrête une minute, se penche comme pour y sentir une fleur, puis pousse un Heiaha ! ricanant et reprend sa belle fuite en bonds divins !...

Heiaha! donc! Pan dévale le coteau et reprend les bonds également divins de sa poursuite $^{73} ! .$.

50 À l'image de Syrinx, le narrateur fait ainsi poser son lecteur en retardant à tout propos une conclusion attendue. Étendre la poursuite, la faire durer, relève en fait de la gageure: le mythe se satisfait très bien de cette syntaxe narrative basique; toute volonté d'entrer dans les détails et l'accessoire nuit en quelque sorte à son intégrité et à son exemplarité : l'anecdotique tue le mythe. Laforgue le sait parfaitement et use à souhait de cette arme. L'extension du mythe se fait ainsi par l'adjonction d'éléments qui ne sont pas constitutifs de ce dernier. Dans Pan et la Syrinx, il ne se passe rien de plus dans la moralité qu'une légendaire poursuite, au dénouement étiologique bien connu. Le mythe est renvoyé à son caractère dépouillé, en même temps qu'il se voit parasité par tout l'appareil discursif romanesque moderne. Il est ici défiguré parce que sa narration même se fait par le biais des nouveaux modes de discours qui ont remplacé la rationalité propre au mythos ${ }^{74}$.

La poursuite est entrecoupée de stations, stations des personnages mais aussi du texte : dialogues, considérations psychologiques, parenthèses narratoriales viennent gonfler le récit initial, sans pour autant constituer des événements nouveaux à proprement parler. Il s'agit pour Laforgue d'opérer toute une série de décalages qui troublent le fonctionnement habituel du discours mythique et légendaire. La distorsion du canevas mythique repose en particulier sur l'introduction de discours et de références exogènes qui contribuent à son décentrement. La moralité devient alors un véritable pot-pourri culturel, qui brasse et nivelle les phraséologies et les représentations de toutes origines.

L'écrivain semble avoir eu à cœur de réaliser le programme sommairement tracé dans cette note datant de 1885 :

Contes pour la jeunesse - Prendre les très populaires contes moraux, et les raconter avec une psychologie réaliste en les faisant tous rater.

Bonaparte montant la faction pour le soldat endormi - Épaminondas à Mantinée etc $^{75}$ -

De fait, l'auteur des Moralités légendaires s'emploie à prendre à rebours les légendes et à psychologiser à outrance ses personnages mythologiques, qu'il s'agisse de Pan et de Syrinx, de Lohengrin et d'Elsa ou du Monstre, de Persée et d'Andromède. Le Dragon parle « d'une voix d'homme distingué qui a eu des malheurs ${ }^{76}$ ", Andromède fait part de velléités mondaines, Pan et Syrinx marivaudent, Lohengrin cherche à déceler chez Elsa la preuve d'une duperie de l'instinct au cours de labyrinthiques duos amoureux. L'humour, l'anachronisme et le burlesque demeurent parmi les moyens les plus efficaces pour saper le mythe et déjouer le poncif.

Pour désorganiser la narration, Laforgue joue également sur son rythme, comme il en perturbe les étapes clés en multipliant les signes parodiques. Le narrateur refuse de prendre son rôle au sérieux et tourne en dérision les phases obligées du récit. En ce qui concerne la situation initiale, nous avons vu que le cadre spatial de chaque moralité s'apparentait d'emblée à un poncif. Les événements perturbateurs sont souvent outrés, à l'image de l'entrée fracassante de Persée; les péripéties de Pan et la Syrinx sont artificiellement dilatées, tandis que les morts s'accumulent comiquement autour de la belle Ruth ; le dénouement de Persée et Andromède est exagérément fantaisiste, ceux de Hamlet et de Salomé nous renvoient à d'autres versions de ces histoires... Ce ne sont là 
que quelques exemples pris au hasard. Par ailleurs, les multiples répétitions qui scandent les textes, en contribuant à brouiller la distinction entre prose et poésie, instaurent aussi des structures cycliques qui suggèrent, de manière plus prosaïque, un enlisement du récit. Sans cesse retardée, différée, l'histoire s'enraye et piétine: le principe même de la progression du récit s'en trouve remis en cause. À l'inverse, des raccourcis intempestifs aux moments cruciaux de l'intrigue sont ménagés pour offusquer le lecteur et le priver de son plaisir : "Allez hop, à Cythère ! ", s'écrie ainsi le fils de Zeus à l'attention d'une Andromède minaudière. Laforgue abrège la scène de délivrance : en convoquant cavalièrement le poncif cythéréen, symbole de l'union des amants, il en chasse un autre, celui du duo amoureux, puisqu'il refuse de composer la scène sentimentale et mélodramatique attendue. "

Pour faire éclater l'arbitraire et le conventionnel des procédés romanesques, le narrateur s'amuse parfois à lancer son destinataire sur une fausse piste, en jouant sur ses habitudes de lecture. Dans Le Miracle des roses, il feint de ménager le suspense et d'introduire un événement pathétique par le procédé bien rodé de l'anticipation, avant de faire un pied de nez au lecteur dupé par l'effet d'annonce :

Il y a dans la vie des minutes absolument déchirantes, déchirantes pour toutes les classes de la société. Celle-ci n'en fut pas, mais il en est; et l'exception ne saurait que confirmer la règle ${ }^{77}$.

56 Au lieu de satisfaire la curiosité éveillée, Laforgue substitue un énoncé proverbial au récit des événements exceptionnels, suggérant ainsi subtilement leur équivalence poncive. Ce genre de palinodies peut aller jusqu'à la rétractation en bonnes et dues formes : c'est alors la légitimité globale du récit qui est mise en cause. À la fin de Hamlet, le narrateur fait part de ses repentirs in extremis, au détour d'un commentaire parenthétique :

À ce moment, on entend dans la nuit toute spectralement claire l'aboi si surhumainement seul d'un chien de ferme à la lune, que le cœur cet excellent Laërtes (qui aurait plutôt mérité, j'y songe, hélas, trop tard, d'être le héros de cette narration) déborde de l'inexplicable anonymat de sa destinée de trente ans ${ }^{78}$ !

57 Ce désaveu de la part de l'instance référente du récit laisse le lecteur perplexe, et l'invite à reconsidérer l'histoire du point de vue d'un faire. Ailleurs, dans Le Miracle des roses, le narrateur attribue malicieusement au Créateur les «épidémies de bizarres scènes» de son histoire, rejetant sur la divinité la responsabilité de péripéties improbables qui lui incombent pourtant de toute évidence. Cette malicieuse mauvaise foi se confirme dans la question rhétorique qui suit : «Et qui les conçut jamais sinon Celui qui règne dans les Cieux ${ }^{79}$ ? La même crédulité feinte est affichée dans Persée et Andromède :

Allons, silence et horizon prêt pour la mortuaire Lune, quand! Oh! bénis soient

les dieux qui envoient, juste au moment voulu, un troisième personnage.

Il arrive comme une fusée, le héros de diamant sur un Pégase de neige ${ }^{80}[\ldots]$

Remarquons au passage l'anachronisme ("comme une fusée») et la superposition abusive de clichés de style dans la caractérisation des personnages (« de diamant », « de neige »), ce qui a pour effet de les discréditer. En feignant avec une maladresse calculée un dégagement total du récit, le narrateur laisse au contraire éclater sa supercherie, et souligne le caractère fictif des événements rapportés. Par la même occasion, il rend intenable la position de simulation qu'occupe aussi son destinataire, qui ne parvient plus à faire semblant de croire à l'histoire racontée. À tous les niveaux, qu'ils soient 
macro- ou microstructurel, les conventions narratives sont sans cesse attaquées, pour la jubilation ou l'agacement du lecteur.

Ainsi, la fin de la moralité nous est souvent révélée dans le cours du récit. Nous avons vu plus haut comment, en dépit de toute vraisemblance, le Monstre, détaché de l'histoire comme de son propre sort, anticipait sur le dénouement de la fable mythologique. Face à l'arrivée aussi tonitruante que ridicule d'un Persée digne d'Offenbach, il se permettait d'annoncer à sa protégée la suite attendue d'événements déjà fixés depuis longtemps par la légende. Tantôt le narrateur respecte de manière excessivement scrupuleuse les données de l'intrigue, tantôt il les modifie de façon flagrante, pour créer de monstrueux hybrides. Il ne s'agit pas pour l'auteur d'opérer des fusions syncrétiques, comme le firent certains symbolistes, mais d'aboutir à d'improbables collages, à de chimériques assemblages dont la viabilité est d'emblée problématique. L'exemple le plus marquant est fourni par Persée et Andromède, qui apparaît comme le fruit d'un greffe du conte de Madame d'Aulnoy sur le canevas ovidien, le tout traité avec la désinvolture de l'opérette. Cette hybridation légendaire qui est au principe de la composition de Persée et Andromède, est mise en abyme dans le discours final du Dragon par l'amalgame comique des quêtes de la Toison d'or et du Graal. Le sommaire monstre marin, qui n'est chez Ovide que la concrétisation d'une vengeance divine, emprunte à la Bête son bon cœur et son intelligence humaine. Il est comme elle victime d'un sortilège, que peut seul briser l'amour sincère d'une jeune fille. Laforgue transplante donc la transformation rédemptrice de la Bête en «jeune homme accompli » à la fin du canevas ovidien, qui ne rapportait qu'une métamorphose secondaire ${ }^{81}$. Ce faisant, il bouscule complètement les données initiales du mythe. Le Monstre y est débonnaire, Persée, insupportable, Andromède, coquette. La tête de Méduse refuse de pétrifier le Monstre parce qu'elle reconnaît en lui « son vieil ami », le «Dragon [...] gardien du jardin des Hespérides ${ }^{82}$ " ... Laforgue a pris un malin plaisir à transformer le valeureux héros mythologique en faux élégant, efféminé, affecté, vulgaire et imbu de sa personne. Il est à noter qu'il possède tous les attributs de la délicatesse féminine: coquet, gracieux, doté comme Salammbô d'une "bouche de grenade ouverte ", il parle "d'une voix sirotée ${ }^{83}$ ». Laforgue brouille les cartes: les valeurs de noblesse, de bravoure et de désintéressement sont transférées, contre toute attente, au Monstre, dont il fait un sage spinozien. Il se produit aussi une autre interversion. Si Persée est devenu un dandy-bellâtre efféminé, la princesse Andromède, au physique androgyne, a de son côté, malgré sa coquetterie, des attitudes bien garçonnes : elle possède un teint hâlé d'un "ton terre cuite lavés ${ }^{84}$ » et son corps est endurci par les éléments. L'inversion de la caractérisation est soulignée avec insistance au moment où Persée s'apprête à enlever Andromède : la jeune fille « va poser son rude pied dans ce délicat étrier ${ }^{85}$ " ... Cette confusion des rôles et des sexes participe d'une intention bouffonne et contribue à déconstruire les données de la légende. Sous les baisers repentants d'Andromède, le Monstre finalement terrassé par Persée (qui est parti sans la jeune femme, vexé par ses rebuffades et la jugeant finalement trop commune) se réveille et se change «en un jeune homme accompli ${ }^{86}$ ». Les rebondissements les plus invraisemblables se succèdent pour finir, qui soulignent l'artifice des procédés romanesques de clôture. Est notamment visée la fameuse scène de reconnaissance, que le roman populaire et feuilletonesque a souvent empruntée au théâtre. 

marque bien la désinvolture la plus totale face au légendaire :

- Noble Andromède, merci. Les temps d'épreuve sont accomplis. Je renais, et je vais renaître correctement pour t'aimer, et qu'il n'y ait ni mot ni minute pour nommer ton bonheur. Mais apprends qui je suis, et quel fut mon destin. J'étais de la race maudite de Cadmus voué aux Furies! Je prêchais la dérision de l'être et le divin du néant dans les bosquets de l'Arcadie. Pour me punir, les dieux de vie me changèrent en Dragon, me condamnant à garder, sous cette forme, les trésors de la terre, jusqu'à ce qu'une vierge m'aimât, moi Monstre, pour moi-même. Dragon à trois tête, j'ai longtemps gardé d'abord les pommes d'or du jardin des Hespérides; Hercule vint et m'égorgea. Puis je passai en Colchide, où devait aborder la Toison d'Or. [...] Et vinrent alors ces étranges Argonautes comme on n'en reverra plus !... Époques splendides! Jason était leur chef, Hercule suivait, et son ami Thésée, et Orphée qui se faisait fort de me charmer avec sa lyre (et qui devait avoir plus tard une fin si tragique !) et aussi les deux Gémeaux; Castor dompteur de chevaux et Pollux habile au pugilat. Époques évanouies !... [...] Enfin je fus égorgé devant cette Toison d'Or du Saint-Graal, grâce aux philtres de Médée qui brûlait d'un amour insensé pour le somptueux Jason. Et les cycles recommencèrent; et j'ai connu Étéocle et Polynice, et la pieuse Antigone, et les perfectionnements de l'armement mettant fin aux temps héroïques. Et enfin l'étrange et accablante Éthiopie, et ton père et toi, ô noble Andromède, Andromède plus belle que toutes, à qui je dois de pouvoir te rendre si heureuse qu'il n'y aura mot ni minute pour nommer ton bonheur ${ }^{87}$.

61 De nature circulaire, le discours de "clôture » du Monstre fait pour ainsi dire le tour des mythes gréco-romains, mis bout à bout les uns les autres et rapidement passés en revue comme un défilé d'images d'Épinal. Le Dragon se présente comme le survivant d'un monde disparu. Vestige d'un âge d'or révolu du mythe, dont il a connu tous les «cycles », il en est comme le témoin et la mémoire, mais son ton grave et solennel, lié aux dévoilements d'identité dont s'accompagnent si souvent les dénouements, demeure de nature avant tout parodique. Cette nuance est confirmée, si besoin était, par certains détails, comme le calque des épithètes homériques, ou encore la parenthèse faite à propos d'Hellé, qui ne cadre pas avec la dignité rhétorique du discours :

Un oracle m'avait fait entendre qu'Hellé serait la vierge promise. Mais elle se noya en voyage, et donna son nom au détroit d'Hellespont. (J'ai su depuis qu'elle n'était pas très jolie ${ }^{88}$ )

Il est à noter que le Dragon semble avoir joué tous les rôles de monstre de la mythologie, qui apparaissent ainsi interchangeables. Cette perspective englobante cherche à rassembler, grâce à la figure composite du Monstre, les récits les plus saillants de la mythologie gréco-romaine (exploits d'Hercule, quête de la Toison d'Or, malédiction des Atrides...) afin de les disqualifier de manière humoristique. Égalisés, énumérés, résumés d'un trait, les mythes sont tous expédiés sans ménagement à la fin de la dernière moralitée ${ }^{89}$, pour être mis au service de l'histoire laforguienne, dont le rocambolesque éclate pleinement dans ce dénouement surchargé, truffé d'explications bavardes.

63 À la fin de la moralité, Laforgue a ménagé en hyperbate une conversation entre "la princesse d'U.E. ", auditrice intradiégiétique, et « Monsieur Amyot de l'Épinal », auquel le récit est attribué a posteriori. La grande dame reproche au conteur les incohérences de son histoire et les libertés prises avec la légende, en blâmant au passage le coup de griffe donné au personnage chevaleresque du sauveur : 
- Ah ! ça, mon cher Monsieur Amyot de l'Épinal, vous nous la bâillez belle avec votre histoire! s'écria la princesse d'U.E. (en ramenant un peu son châle, car cette splendide nuit était fraîche). Moi qui avais donné tout autrement mon cœur à cette aventure de Persée et d'Andromède ! je ne vous chicanerai pas sur la façon dont vous avez travesti ce pauvre Persée. (Je vous le pardonne en faveur de la main de maître dont vous m'avez flattée à l'antique, s'entend, sous les traits d'Andromède.) Mais le dénouement de l'histoire! Qu'est-ce que ce Monstre à qui nul ne s'est intéressé jusqu'ici ${ }^{90}$ ? [...] dans un contexte de distractions princières. Ce débat conclusif autour de la construction du récit rappelle évidemment les pauses dialoguées introduites par Boccace entre les nouvelles du Décaméron, qui ont inspiré à Marguerite de Navarre son Heptaméron. Les infractions au genre éclatent cependant rapidement. Le conteur porte d'abord un nom lourd de significations parodiques, puisqu'il couple le patronyme du célèbre prélat ${ }^{91}$, traducteur de Plutarque, à celui de l'Imagerie vosgienne. Le rapprochement suggère que les modèles héroïques transmis par la belle plume de l'helléniste relèvent de la fabrique de chromos. Si besoin était, la suspicion est une nouvelle fois jetée sur l'énonciateur au terme d'un récit qui, sans surprise, ne joue guère son rôle étiologique ${ }^{92}$. Au lieu d'expliquer, comme il se devrait, l'origine et la position des constellations éponymes de Persée et Andromède, l'auteur défend sa fantaisie personnelle et refuse de se conformer aux évidences, en concluant à l'inconséquence des cieux, qu'il qualifie de «sereins et conventionnels ${ }^{93} »$. Enfin, les personnages négligent de tirer la «moralité » de l'histoire pour aller « prendre le thé ». La réparation in extremis de cet oubli montre bien quel rôle accessoire et facultatif est désormais dévolu à la " morale de l'histoire ", qui n'est plus présente que par habitude et convention, mais se trouve en réalité vidée de sens. En même temps qu'il porte l'estocade au genre du conte moral, Laforgue revendique par cet épilogue humoristique les droits absolus de l'auteur à transgresser les normes et les traditions pour affirmer son originalité. En position d'auditrice, la princesse d'U.E. représente une sorte de double du lecteur et exprime justement sa frustration: "Moi qui avait donné tout autrement mon cœur à cette aventure de Persée et d'Andromède!» Le terme de «cœur " n'est pas anodin: Laforgue refuse de flatter les attentes d'un lectorat jugé «féminin», qui recherche le pittoresque et l'effusion sentimentale, et il méprise joyeusement « l'art [...] de servir à point un dénouement bien cuit ${ }^{94} »$. Il ne s'agit pas de combler les aspirations de lecteurs en mal d'aventures et de projections identificatoires. Si le mythe a perdu ses attributions herméneutiques, il ne sera donc pas pour autant récupéré par les formes les plus courantes de la fiction romanesque. L'exemple du dénouement et de l'épilogue de Persée et Andromède donne une bonne idée de la manière dont Laforgue tourne en ridicule des séquences narratives types, placées sous le signe du poncif.

À l'instar de l'incipit, le dénouement représente bien entendu un moment capital dans cette stratégie auctoriale résolument anti-romanesque. Dans Salomé et dans Hamlet, la banalité du sujet est ouvertement énoncée à la fin de la moralité. En effet, au lieu d'insister pour finir sur l'originalité, l'exemplarité ou la véracité de son histoire, le narrateur la déprécie sciemment en énonçant en conclusion le caractère interchangeable des héros éponymes: "Un Hamlet de moins; la race n'en est pas perdue, qu'on se le dise ${ }^{95}$ !» La restriction insérée dans la clausule de Salomé (qui parodie celle de Salammbô) va dans le même sens : 
Ainsi connut le trépas, Salomé, «du moins celle des Iles Blanches Esotériques »; moins victime des hasards illettrés que d'avoir voulu vivre dans le factice et non à la bonne franquette, à l'instar de chacun de nous ${ }^{96}$. il ne constitue plus qu'une version anodine parmi bien d'autres et vient s'inscrire dans une longue série, ce qui le rapproche du poncif. La désinvolture affichée à l'égard de la légende autorise ainsi une redéfinition complète de l'acte narratorial. La refondation du récit passe par une réflexion sur les procédés romanesques, dont Laforgue déjoue le caractère convenu. La profusion et la superposition des références invitent à lire les Moralités comme des textes saturés de culture, conscients de la présence des mots d'autrui dans tout discours. La prise de parole purement individuelle y est clairement présentée comme un leurre, et l'intérêt narratif des Moralités réside, non pas dans le déroulement maitrisé d'une histoire originale, mais dans le jeu de reconnaissance culturelle et dans le décryptage de codes romanesques perturbés, maniés à contreemploi par un conteur espiègle.

Conclusion attention s'est focalisée sur ce que les textes laforguiens «donnaient à lire » comme poncifs. On peut se demander pourquoi Laforgue a mis ici un tel acharnement à dénuder les procédés narratifs et fictionnels en les assimilant sans équivoque à des structures stéréotypées, bonnes à bafouer, à contourner et à parodier.

D'un point de vue intellectuel et esthétique, Laforgue condamne le poncif, en particulier dans sa critique d'art. Néanmoins, l'un des mérites de l'auteur des Moralités légendaires est d'avoir compris de manière intuitive, au moment où balbutiait la science linguistique, la configuration nécessairement collective de la langue, ainsi que la présence, dans toute narration, de structures récurrentes qui ont tendance à se stabiliser et à se figer.

Plutôt que de refuser cet ordre des choses, Laforgue s'est employé à l'assumer, avec une remarquable maturité critique. La déconstruction du récit est pour lui un moyen de neutraliser les poncifs en les manipulant en toute connaissance de cause. Elle lui permet aussi d'associer étroitement le lecteur à la construction de l'objet-récit, en sollicitant de sa part une forme de complicité culturelle, fondée notamment sur l'explicitation d'une certaine topicité narrative. En compromettant l'intégrité et la vraisemblance du récit, la mise en évidence des topoï déporte l'attention et le plaisir du lecteur vers les processus créatifs et l'agencement textuel. En définitive, l'attitude de Laforgue face aux poncifs est ambiguë: l'écrivain ne cherche pas à évincer les phénomènes stéréotypiques, mais plutôt à les apprivoiser, en les utilisant au second degré. Ce faisant, malgré leur statut parodique, ces derniers s'affirment bien comme des unités fondamentales du récit, de même qu'ils demeurent gage d'intelligibilité et de partage. 


\section{BIBLIOGRAPHIE}

Le cliché, Actes du Colloque international et interdisciplinaire d'Aix-en-Provence (1996), sous la direction de G. Mathis, Toulouse, Presses Universitaires du Mirail, 1998.

Lieux communs, topoï, stéréotypes, clichés. Linguistique, argumentation rhétorique, analyse des discours littéraires et sociaux, Actes du Colloque de l'Université de Lyon II (1992), sous la direction de C. Plantin, Paris, Kimé, 1994.

Le stéréotype : crise et transformations, Actes du Colloque de Cerisy-la-Salle (1993), sous la direction d'A. Goulet, Caen, Presses Universitaires de Caen, 1994.

AMOSSY (Ruth), « The Cliché in the Reading Process », Sub-Stance, n. 35, 1982, pp. 34-45.

ID., « Stereotypes and Representation in Fiction », Poetic Today, n. 5, 1986, pp. 689-700.

ID., « La notion de stéréotype dans la réflexion contemporaine », Littérature, n. 73, février 1989, pp. 29-46.

ID., « Commonplace knowledge and innovation », Sub-Stance, n. 62-63, 1990, pp. 145-156.

ID., Les idées reçues. Sémiologie du stéréotype, Paris, Nathan, 1991.

AMOSSY Ruth, HERSCHBERG-PIERROT Anne, Stéréotypes et clichés. Langue, discours, société, Paris, Nathan, 1997.

AMOSSY Ruth, ROSEN Elisheva, Les discours du cliché, Paris, CDU-SEDES, 1982.

COMPAGNON Antoine, La seconde main, ou le travail de la citation, Paris, Seuil, 1979.

ID., « Théorie du lieu commun », Cahiers de l'Association internationale des études françaises, n. 49, mai 1997, pp. 23-37.

GENETTE Gérard, Palimpsestes. La littérature au second degré, Paris, Seuil, 1982.

GIARDINA Calogero, « Les renouvellements des clichés de langue dans les Moralités légendaires de Jules Laforgue », Les Lettres romanes, n. 4, vol. 86, novembre 1992, pp. 193-305.

GOYET Francis, " Aux origines du sens actuel de 'lieu commun' », Cahiers de l'Association internationale des études françaises, n. 49, mai 1997, pp. 59-74.

GROJNOWSKI Daniel, « Moralité légendaire », Revue générale des publications françaises et étrangères, n. 34, 1978, pp. 63-71.

HANNOOSH Michele, Parody and Decadence. Laforgue's 'Moralités légendaires', Columbus, Ohio State, 1989.

HERSCHBERG-PIERROT Anne, «Problématiques du cliché : sur Flaubert », Poétique, n. 43, 1980, pp. 334-345.

JENNY Laurent, « Structure et fonction du cliché », Poétique, n. 12, 1972, pp. 495-517.

LAROCHE Hervé, Dictionnaire des clichés littéraires, Paris, Arléa, 2001.

PLANTIN Christian, Lieux communs, stéréotypes, clichés, Paris, Kimé, 1993.

RIFFATERRE Michaël, Essais de stylistique structurale, Paris, Flammarion, 1971 [cf. notamment le chapitre IV]. 


\section{NOTES}

1. Jean Molino, «La culture du cliché. Archéologie critique d'une notion problématique ", in Le cliché, Actes du Colloque international et interdisciplinaire d'Aix-en-Provence (1996), sous la direction de G. Mathis, Toulouse, Presses universitaires du Mirail, 1998, p. 35.

2. Topique (au masculin) et topos sont donc presque synonymes, le premier conservant cependant un sens plus technique.

3. Au masculin, l'adjectif substantivé topique, emprunté à la terminologie aristotélicienne, désigne, de même, un « lieu commun ».

4. Ruth Amossy, « Du cliché et du stéréotype. Bilan provisoire ou anatomie d'un parcours ", in Le cliché, op. cit., p. 24.

5. Le terme est employé aussi bien dans le vocabulaire technique de la fresque, de la céramique, de la peinture que dans celui de la broderie.

6. Charles Baudelaire, Salon de 1846, X. «Du chic et du poncif », in Euvres complètes de Baudelaire, Paris, Gallimard, 1976, t. II, p. 468.

7. Voici le passage en question : «La signification du mot poncif a beaucoup d'analogie avec celle du mot chic. Néanmoins, il s'applique plus particulièrement aux expressions de tête et aux attitudes./Il y a des colères poncif, des étonnements poncif, par exemple l'étonnement exprimé par un bras horizontal avec le pouce écarquillé./Il y a dans la vie et dans la nature des choses et des êtres poncif, c'est-à-dire qui sont le résumé des idées vulgaires et banales qu'on se fait de ces choses et de ces êtres : aussi les grands artistes en ont horreur./Tout ce qui est conventionnel et traditionnel relève du chic et du poncif./Quand un chanteur met la main sur son cœur, cela veut dire d'ordinaire : je l'aimerai toujours! - Serre-t-il les poings en regardant le souffleur ou les planches, cela signifie : il mourra, le traître ! - Voilà le poncif. » (Charles Baudelaire, Salon de 1846, X. « Du chic et du poncif », op. cit., p. 468).

8. Expression employée par Jules Laforgue dans sa "Complainte du foetus de Poète » (Jules Laforgue, Les Complaintes, "Complainte du fotus de Poète », v. 7, in Ceuvres complètes [désormais O. C.], Lausanne, L'Âge d'homme, 1986-2000, t. I [1986], p. 563). 9. Ruth Amossy, «Du cliché et du stéréotype. Bilan provisoire ou anatomie d'un parcours ", in Le cliché, op. cit., p. 21.

10. Anne-Marie Perrin Naffakh définit le cliché de style comme « un énoncé " $1^{\circ}$ " dont l'étendue va du mot unique [...] à la phrase simple, le syntagme nominal ou verbal étant sa structure majoritaire »; $2^{\circ}$ " accordé en synchronie au système linguistique des textes où il entre, l'archaïsme y étant exceptionnel »; $3^{\circ}$ " conciliant une stabilité générale d'organisation et de signification, qui permet de l'identifier dans des contextes différents, avec des variantes morphologiques, syntaxiques et lexicales qui lui sont accordées dans des limites à déterminer "; $4^{\circ}$ " connaissant une diffusion d'emploi telle qu'il ne se confond ni avec l'énoncé autonyme, ni avec la parole individuelle, ni avec les habitudes langagières d'une époque ou les manies d'écriture d'une école "; $5^{\circ}$ " préservant une part réduite mais effective de la valeur figurative de son élément rhétorique » et, enfin, $6^{\circ}$ " assigné au niveau de l'élocution soutenue, et, pour l'essentiel, aux genres littéraires élevés » (Anne-Marie Perrin-Naffakh, Le cliché de style en français moderne : nature linguistique et rhétorique, fonction littéraire, Bordeaux, Presses universitaires de Bordeaux, 1985, pp. 75-76).

11. Société pour l'analyse de la topique narrative. 
12. Michelle Weil, "Comment repérer et définir le topos ? ", in La naissance du roman en France : topique romanesque de L'Astrée à Justine, sous la direction de N. Boursier et D. Trott, Paris-Seattle-Tübingen, 1990, pp. 123-137.

13. Michael Riffaterre, Essais de stylistique structurale, Paris, Flammarion, 1971, p. 162.

14. Ruth Amossy et Elisheva Rosen, Les discours du cliché, Paris, C.D.U.-S.E.D.E.S., 1982,

p. 9.

15. Cette perception subjective du banal pourrait prendre le nom de topicité, comme le suggère la Sator. La topicité serait alors une sorte de seuil subjectif qui sépare le récurrent ou le figé du poncif ; elle correspondrait aux conditions, variables avec le récepteur, qui rendraient effective, pour un sujet donné, l'assimilation d'un phénomène récurrent à un topos. Un texte peut d'ailleurs lui-même désigner certains objets comme topiques (c'est en particulier le cas de la parodie), voire s'auto-désigner comme tel. Cela confirmerait, si besoin était, le fait que les effets de réception sont aussi internes aux œuvres, et ne concernent pas que le lectorat : tout texte est déjà un effet de lecture. La notion de topicité pourrait se révéler particulièrement intéressante pour étudier les phénomènes de reconnaissance, les allusions intertextuelles élargies et les entraves aux conventions que les textes proposent à leurs destinataires. Nous pensons à des œuvres, comme par exemple les Contes cruels de Villiers, qui jouent avec les codes fictionnels en invitant à savourer le réagencement des modèles narratifs connus. La topicité fonctionne en effet comme un mode de connivence de nature métatextuelle particulièrement fécond entre narrateur et narrataire, et à ce titre, mériterait certainement une attention plus grande de la part de la critique.

16. Henri Quéré, « Le cliché : pour et contre », in Le cliché, op. cit., p. 110.

17. Laforgue écrit à son protecteur Charles Éphrussi : «Pour moi, laissez-moi vous écrire souvent, à l'aventure, vous racontant n'importe quoi, avec toujours cette épigraphe sous-entendue : nil sub sole novum ou plutôt omne sub sole novum. » (Lettre à Charles Éphrussi datée du 31 décembre 1881, in Jules Laforgue, O. C., t. I, p. 736.) On voit que la formule est néanmoins réversible, sans quoi, il deviendrait impossible de continuer à écrire.

18. Jules Laforgue, Paul Bourget (1882), in O. C., t. III, p. 129-130.

19. Jules Laforgue, Paul Bourget (1882), op. cit., p. 128.

20. Jules Laforgue, Lettre à Gustave Kahn datée du 3 juin 1886, in O. C., t. II, p. 852.

21. Jean-Pierre Vernant, Mythe et société en Grèce ancienne, Paris, F. Maspero, 1974, p. 206.

22. Gustave Flaubert, Lettre à Jules Duplan datée du 28 mai 1857.

23. Jules Laforgue, Lettre à Gustave Kahn datée du 17 novembre 1885, O. C., t. II, p. 803.

24. Jules Laforgue, Des Fleurs de bonne volonté, XVI, « Dimanches », v. 15-16, O. C., t. 2 , p. 180.

25. Conte paru dans Le Journal du 18 juin 1898 et repris dans Princesses d'ivoire et d'ivresse en 1902.

26. Jules Laforgue, Moralités légendaires, Hamlet ou les suites de la piété filiale, O.C., t. II, p. 379.

27. Id.

28. Jules Laforgue, Lettre à Marie Laforgue datée du 14 mai 1883, O. C., t. I, p. 821.

29. On sait la place qu'il occupe dans les contes. La transformation en crapaud, animal vil associé à la sorcellerie, indique généralement un châtiment ou un maléfice. Chez Corbière, il devient le représentant symbolique du poète disgracié. Laforgue associe lui aussi la laideur et l'aspect répugnant de la bête à un discours ou un chant, de nature 
chorale. Le chœur de la tragédie antique a cédé la place à un concert de batraciens : cette mise en scène participe du rabaissement burlesque de la fable, et signale la parodie.

30. Jules Laforgue, Moralités légendaires, Hamlet ou les suites de la piété filiale, O.C., t. II, p. 379 .

31. Daniel Grojnowski note à juste titre cette dilution de la cible parodique, caractéristique des Moralités légendaires (cf. Daniel Grojnowski, « Moralité légendaire », Critique, n. 368, janvier 1978, pp. 63-71).

32. Jules Laforgue, Moralités légendaires, Hamlet ou les suites de la piété filiale, O. C., t. II, p. 380 .

33. Ce sont les premiers mots de la nouvelle. L'expression, avec des variantes, scande toute la première partie de la moralité, à la manière d'un leitmotiv.

34. Jules Laforgue, Moralités légendaires, Hamlet ou les suites de la piété filiale, O. C., t. II, p. 379.

35. Juliette, l'héroïne, veut « s'établir en son petit coin pour bien songer à ses affaires à elle en face de la lune et de la mer qui appartiennent à tout le monde » (Les deux Pigeons, O. C., t. II, p. 490).

36. Jules Laforgue, Moralités légendaires, Persée et Andromède ou le plus heureux des trois, O. C., t. II, p. 470.

37. Jules Laforgue, Moralités légendaires, Persée et Andromède ou le plus heureux des trois, O. C., t. II, p. 469.

38. Jules Laforgue, Moralités légendaires, Persée et Andromède ou le plus heureux des trois, O. C., t. II, pp. 469-470.

39. Jules Laforgue, Moralités légendaires, Le Miracle des roses, O. C., t. II, p. 403.

40. Jules Laforgue, Moralités légendaires, Pan et la Syrinx ou l'invention de la flûte à sept tuyaux, O. C., t. II, p. 451.

41. Jules Laforgue, Moralités légendaires, Pan et la Syrinx ou l'invention de la flûte à sept tuyaux, O. C., t. II, p. 461.

42. Jules Laforgue, Moralités légendaires, Pan et la Syrinx ou l'invention de la flûte à sept tuyaux, O. C., t. II, p. 458.

43. Jules Laforgue, Moralités légendaires, Pan et la Syrinx ou l'invention de la flûte à sept tuyaux, O. C., t. II, p. 458.

44. Jules Laforgue, Moralités légendaires, Pan et la Syrinx ou l'invention de la flûte à sept tuyaux, O. C., t. II, p. 460.

45. Daniel Grojnowski, Aux commencements du rire moderne. L'esprit fumiste, Paris, Corti, 1997, p. 103.

46. Jules Laforgue, « Notes sur Corbière », Entretiens politiques et littéraires, avril et juillet 1891, repris dans : O. C., t. III, p. 183.

47. Chaque récit a évidemment un narrateur particulier, avec des caractéristiques qui peuvent différer. Ainsi, le narrateur du Miracle des roses revendique un lien affectif puissant avec la ville d'eaux qui sert de théâtre à la nouvelle (" O petite ville, vous avez été mes seules amours, mais en voilà assez. Depuis qu'elle (Elle) est décédée, je n'y reviens guère [...] », O.C., t. II, p. 404). Nous sommes donc proches d'un narrateur intradiégétique, ce qui sera le cas dans Persée et Andromède, mais pas dans les autres nouvelles. Malgré des différences de cadre énonciatif, les instances qui prennent en charge le récit ont cependant tant de caractéristiques communes, que l'ont peut conclure à une grand homogénéité narratoriale dans le recueil. On nous permettra 
donc de parler, par commodité, « du » narrateur des Moralités, étant entendu que cette expression renvoie à un pluriel d'entités, réunies par leurs similitudes.

48. Ainsi, contrairement à beaucoup de réécritures du mythe de Salomé qui attribuent à la jeune femme fatale un amour secret pour le prophète, chez Laforgue, c'est ce dernier qui est amoureux de la fille du Tétrarque. De manière plus flagrante, Lohengrin rompt la tension tragique du drame wagnérien en révélant d'emblée son identité. Quant à Persée et Andromède, le récit donne lieu à un véritable renversement axiologique : le Monstre y devient un personnage sympathique de philosophe désabusé, dépourvu de toute agressivité, tandis que le héros, traité sur le mode burlesque, est affublé de traits de caractères horripilants.

49. Cette artificialité touche en particulier Persée, qualifié de " vilain héros d'opéracomique " (Jules Laforgue, Moralités légendaires, Persée et Andromède ou le plus heureux des trois, O.C., t. II, p. 481).

50. Jules Laforgue, Moralités légendaires, Salomé, O. C., t. II, p. 433.

51. Jules Laforgue, Moralités légendaires, Lohengrin, fils de Parsifal, O. C., t. II, p. 421.

52. Emprunt manifeste dans une phrase comme celle-ci : « Le prince Hamlet en a comme ça long sur le cœur, plus long qu'il n'en tient en cinq actes ». (Hamlet ou les suites de la piété filiale, O. C., t. II, p. 381). Il est intéressant de noter que les Moralités font plusieurs allusions appuyées à l'opéra-comique. Le sous-titre de Persée et Andromède, qui évoque le théâtre boulevardier et ses ménages adultères, est justement emprunté à une pièce d'Eugène Labiche, écrite en collaboration avec Edmond Gondinet et créée le 11 janvier 1870 au Théâtre du Palais-Royal. Le Miracle des roses mentionne dès la première phrase « des montagnards rapaces et nullement opéra-comique malgré leur costume ", ce qui laisse tout de même entendre une ressemblance superficielle, ne fûtelle qu'ornementale. Hamlet se réjouit de la mort prématurée d'Ophélie, qui lui aura permis d'échapper à « une vilaine réputation de Belle-Hélène ». Dans Salomé, la description initiale plante d'emblée un décor de carton-pâte : « le palais tétrarchique n'était qu'un monolithe, dégrossi, excavé, évidé, aménagé et finalement poli en un mont de basalte noir jaspé de blanc [...], l'air d'une éponge ossifiée, tendant un joli phare d'opéra-comique aux jonques noctambules. » La scène, qu'il s'agisse de l'alcazar, de l'opéra ou de la tragédie, est omniprésente dans les Moralités. Le terme de « moralité » renvoie d'ailleurs autant au genre du conte moral et de l'apologue qu'au théâtre allégorique du Moyen-âge. Les allusions scéniques ont de multiples fonctions, et cette contamination théâtrale des nouvelles mériterait une étude à part entière. Dans le cas des références à l'opéra-comique, les plus nombreuses, il s'agit plutôt d'assimiler la fable à une farce bouffonne, de rabaisser le mythe par le burlesque, de transformer les personnages en pantins. La transparence des références incite aussi à considérer les Moralités légendaires comme autant de mises en scène, au caractère artificiel revendiqué. Dans l'une de ses «Chroniques parisiennes» de 1879, Laforgue évoque avec dédain «Cendrillon! la féerie qui exhibe le plus de trucs, de trappes, de ballets et de maillots. » Le modèle de l'opéra-comique fonctionne comme un repoussoir et son amalgame avec le mythe sert l'entreprise de dévalorisation dans laquelle s'est lancé l'auteur. Cependant, la moralité emprunte aussi tout un mode opératoire aux " pièces à décor » : comme dans ces dernières, l'attention du destinataire sera retenue par des costumes et des compositions voyants, une machinerie à grands effets et de spectaculaires changements à vue. Laforgue entend ainsi exhiber les grosses ficelles narratives et en démontrer le caractère artificiel.

53. Jules Laforgue, Moralités légendaires, Lohengrin, fils de Parsifal, O. C., t. II, p. 417. 
54. Jules Laforgue, Moralités légendaires, Lohengrin, fils de Parsifal, O. C., t. II, p. 417.

55. C'est le terme même utilisé par Elsa dans sa prière devant « l'horizon tout enchanté des mers » (Jules Laforgue, Moralités légendaires, Lohengrin, fils de Parsifal, O. C., t. II, p. 419 et $\mathrm{p} .418$ pour la dernière citation.)

56. Qui s'inspire néanmoins de plusieurs sources, notamment le cycle arthurien du Graal et le conte d'Amour et Psyché inséré dans les Métamorphoses d'Apulée.

57. «Infini, montre un peu tes papiers! " (L'Imitation de Notre-Dame la Lune, « Nobles et touchantes divagations sous la Lune », v. 24, O. C., t. II, p. 107.) Le chevalier décline de lui-même son identité, en détrompant aimablement ceux qui le prennent pour Endymion : «J'arrive tout droit de Saint-Graal. Parsifal est mon père ; je n'ai jamais connu ma mère. Je suis Lohengrin, le Chevalier-Errant, le lis des croisades futures pour l'émancipation de la Femme. » (Jules Laforgue, Moralités légendaires, Lohengrin, fils de Parsifal, O. C., t. II, p. 420.) On voit que Laforgue imprime un sens très personnel à la fonction du héros, venu non pas sauver la pure Elsa, mais le genre féminin en général. Le caractère universel de sa mission était annoncé par sa désignation initiale : « Lui » veut délivrer « Elle ».

58. Jules Laforgue, Moralités légendaires, Persée et Andromède ou le plus heureux des trois, O. C., t. II, p. 477.

59. D'une manière analogue, l'exclamation « Ah, il faut bien en finir ! ", intervient au moment où Persée invite Andromède à le suivre après avoir tué le Monstre. Imputable au narrateur ou à Andromède par le biais du style indirect libre, elle renvoie, au niveau métatextuel, au caractère obligé du dénouement, défini par Ovide et la fable mythologique. On sait que Laforgue se fera cependant une joie de le recomposer. 60. Jules Laforgue, Moralités légendaires, Persée et Andromède ou le plus heureux des trois, O. C., t. II, p. 478.

61. Jules Laforgue, Moralités légendaires, Persée et Andromède ou le plus heureux des trois, O. C., t. II, p. 478.

62. Jusqu'au dénouement, où l'on bascule dans la fantaisie bouffonne, le Monstre demeure le représentant du pôle tragique et use d'une langue châtiée, tandis qu'Andromède, tentée par l'échappatoire vaudevillesque ou féerique, s'exprime dans un registre courant et souvent familier. Dans la moralité, elle laisse à tout propos échapper des préoccupations futiles qui ne cadrent pas avec la dignité légendaire du personnage, ni même avec le portrait d'adolescente sauvageonne qui en est dressé. Elle s'exclame par exemple : «-Si du moins tu voulais me prendre sur ton dos, et me transporter dans des pays où l'on trouve de la société. (Ah, je voudrais tant me lancer dans le monde !) » (Jules Laforgue, Moralités légendaires, Persée et Andromède ou le plus heureux des trois, O. C., t. II, p. 471.) Il en est de même d'Elsa qui veut se regarder dans un miroir avant d'avoir les yeux brûlés, et peste contre les bousculades qui risquent de froisser sa robe au moment où paraît Lohengrin. Les jeunes filles sont aussi associées à une certaine littérature sentimentale, qui leur sert d'idéal moral et de code de conduite. Andromède exprime ainsi ses « doléances romanesques » au Monstre (id., p. 471). Les héroïnes mythiques héritent ainsi de la futilité moderne et de préoccupations psychosociales.

63. Jules Laforgue, Moralités légendaires, Hamlet ou les suites de la piété filiale, O. C., t. II, p. 388.

64. Jules Laforgue, « Notes sur Baudelaire », Entretiens politiques et littéraires, avril et juillet 1891, repris dans : O. C., t. III, p. 179. 
65. Ovide, Les Métamorphoses, Livre I, v. 698-716, trad. de J. Chamonard, Paris, Garnier, 1966, p. 61.

66. Nous ne pensons pas ici spécialement à Virgile, qui propose déjà des versions très littéraires des mythes, mais plutôt à des textes comme la Genèse, où le récit de la Chute, qui tient en quelques lignes, n'en a pas moins inspiré des gloses infinies. Le mythe se reconnaît à son pouvoir expansif et germinal, qui n'est pas à notre sens exclusivement lié à des qualités intrinsèques, mais procède sans doute avant tout d'un effet de réception : pour des raisons complexes, historiques, sociologiques, culturelles, psychiques, littéraires et autres, certains récits suscitent par la suite une frénésie de réécriture et de réinterprétation. La preuve en est que chaque époque a ses configurations privilégiées. On note ainsi une multiplication des variations autour de Salomé et de Hamlet pendant la période symboliste, engouement dont témoigne de manière parodique le recueil des Moralités, alors que cette vogue s'a pas encore atteint son acmé.

67. Jules Laforgue, Moralités légendaires, Salomé, O. C., t. II, p. 435.

68. Les signes merveilleux accompagnant la naissance de l'individu exceptionnel sont un motif fondamental dans les mythes, contes et légendes, mais « l'éclair » qui vient « calligraphier alpha et oméga » dans le ciel prend pour cible parodique plus précise l'avertissement divin du festin de Balthazar. Or, il est à noter qu'aucun Daniel ne vient déchiffrer l'énigme, balayée d'un revers de main par le tétrarque blasé : le mythe perd ici tout pouvoir étiologique.

69. Jules Laforgue, Moralités légendaires, Pan et la Syrinx ou l'invention de la flûte à sept tuyaux, O. C., t. II, p. 457.

70. Jules Laforgue, Moralités légendaires, Pan et la Syrinx ou l'invention de la flûte à sept tuyaux, O. C., t. II, p. 458.

71. Jules Laforgue, Moralités légendaires, Pan et la Syrinx ou l'invention de la flûte à sept tuyaux, O. C., t. II, p. 460.

72. Jules Laforgue, Moralités légendaires, Pan et la Syrinx ou l'invention de la flûte à sept tuyaux, O. C., t. II, p. 461.

73. Jules Laforgue, Moralités légendaires, Pan et la Syrinx ou l'invention de la flûte à sept tuyaux, O. C., t. II, p. 461.

74. Nous en trouvons un exemple significatif dans l'épisode du procès d'Elsa. Wagner s'appuyait sur le modèle archaïque de l'ordalie, qui sied mieux à l'atmosphère légendaire. Laforgue, lui, mêle au cérémonial parodique du «Concile Blanc » le lexique juridique moderne, sa syntaxe froide et ses tournures administratives : «"Elsa, Vestale assermentée, gardienne des Mystères, des philtres, des formules et du froment des brioches nuptiales, qu'as-tu fait de la clef de ton répertoire ? [...] Que répondrais-tu, par exemple ?' » Après les protestations d'innocence de l'accusée, le « vicaire de DianeArtémis » cède la parole à un autre prélat de fantaisie : «Et le confesseur d'Hécate, surgissant à son tour, déroule l'acte d'accusation./'Dans la nuit du ... etc., etc.' » (Jules Laforgue, Moralités légendaires, Lohengrin, fils de Parsifal, O. C., t. II, p. 417.) Loin de gagner en réalisme, le mythe perd toute crédibilité « légendaire » à être ainsi frotté à d'autres types de discours exogènes, qui portent atteinte à sa cohérence interne.

75. Jules Laforgue, Feuilles volantes, Notes d'un carnet de 1885 [publiées pour la plupart dans La Revue Blanche du 15 juin 1895], n. 25, repris dans : O. C., t. III, p. 1018.

76. Jules Laforgue, Moralités légendaires, Persée et Andromède ou le plus heureux des trois,

O. C., t. II, p. 470.

77. Jules Laforgue, Moralités légendaires, Le Miracle des roses, O. C., t. II, p. 410-411. 
78. Jules Laforgue, Moralités légendaires, Hamlet ou les suites de la piété filiale, O. C., t. II, p. 399.

79. Jules Laforgue, Moralités légendaires, Le Miracle des roses, O. C., t. II, p. 409.

80. Jules Laforgue, Moralités légendaires, Persée et Andromède ou le plus heureux des trois, $O$. C., t. II, p. 477.

81. Le lit d'algues sur lequel Persée a déposé la tête de Méduse après sa victoire sur le monstre se pétrifie pour créer le corail.

82. Jules Laforgue, Moralités légendaires, Persée et Andromède ou le plus heureux des trois,

O. C., t. II, p. 481.

83. Jules Laforgue, Moralités légendaires, Persée et Andromède ou le plus heureux des trois, O. C., t. II, p. 480. On retrouve au passage la tendance décadente à féminiser de grandes figures masculines.

84. Jules Laforgue, Moralités légendaires, Persée et Andromède ou le plus heureux des trois, O. C., t. II, p. 472.

85. Jules Laforgue, Moralités légendaires, Persée et Andromède ou le plus heureux des trois, O. C., t. II, p. 479.

86. Jules Laforgue, Moralités légendaires, Persée et Andromède ou le plus heureux des trois, O. C., t. II, p. 482.

87. Jules Laforgue, Moralités légendaires, Persée et Andromède ou le plus heureux des trois, O. C., t. II, pp. 481-482.

88. Jules Laforgue, Moralités légendaires, Persée et Andromède ou le plus heureux des trois, O. C., t. II, p. 482.

89. Il existe un débat à ce sujet : Édouard Dujardin a préparé l'édition en volume (posthume) des Moralités légendaires et tout porte à croire qu'il a scrupuleusement respecté les dernières volontés de l'auteur. Néanmoins, on remarque que l'ordre initial des nouvelles prévu par Laforgue a finalement été modifié : le récit Pan et la Syrinx, qui succédait à Persée et Andromède, a été placé en tête du recueil pour l'édition en volume (et la nouvelle Les deux Pigeons écartée, avec l'accord explicite de l'auteur). Certains, comme Daniel Grojnowski, y voient une initiative personnelle de Dujardin, mais cette hypothèse ne peut être vérifiée.

90. Jules Laforgue, Moralités légendaires, Persée et Andromède ou le plus heureux des trois, O. C., t. II, pp. 482-483.

91. Le nom de Jacques Amyot est d'ailleurs lié à Marguerite de Navarre : ce fut notamment elle qui lui procura son appui pour obtenir la chaire de lecteur de latin et de grec à l'université de Bourges.

92. «[I]l n'y a jamais moyen de discuter et de s'instruire avec vous », blâme la princesse (Jules Laforgue, Moralités légendaires, Persée et Andromède ou le plus heureux des trois, O. C., t. II, p. 483).

93. Jules Laforgue, Moralités légendaires, Persée et Andromède ou le plus heureux des trois, O. C., t. II, p. 483.

94. Jules Laforgue, Tessa, II, 5, v. 247-248, O. C., t. I, p. 134.

95. Jules Laforgue, Moralités légendaires, Hamlet ou les suites de la piété filiale, O. C., t. 2, p. 400.

96. Jules Laforgue, Moralités légendaires, Salomé, O. C., t. 2, p. 447. Nous soulignons. 


\section{RÉSUMÉS}

Le recueil des Moralités légendaires constitue un objet d'étude de choix lorsqu'on s'intéresse à la manipulation d'unités narratives préconstruites. Nous nous proposons d'analyser la manière dont Laforgue y exhibe les ficelles de la narration, en les désignant à l'attention du lecteur comme des « poncifs", terme qu'il conviendra de définir avec précision. Par cette configuration fondamentale, l'écriture laforguienne sollicite fortement la relation entre narrateur et narrataire tout comme elle interroge en profondeur les modèles génériques et l'horizon d'attente du destinataire.

INDEX

Mots-clés : littérature française, habitudes de réception, conventions narratives, métatextualité, mythes, terminologie, poncif , Laforgue, parodie, intertextualité, réécriture

Index chronologique : XIXe siècle

\section{AUTEUR}

ALISSA LE BLANC

Agrégée de lettres modernes, Docteur en littérature française, telem (Université de Bordeaux III) 